\title{
CIUDAD E ILUSTRACIÓN. TRANSFORMACIONES URBANAS EN SEVILLA (1767-1823)
}

\section{City and Enlightenment. Urban Transformations in Seville (1767-1823)}

\author{
Francisco OLLERO LOBATO \\ Universidad Pablo de Olavide \\ folllob@upo.es
}

Fecha de recepción: 20/06/2014

Fecha de aceptación definitiva: 12/01/2015

RESUMEN: El presente artículo estudia los cambios que se producen durante la Ilustración en Sevilla, tanto en la idea de la ciudad como conjunto como en las transformaciones que experimenta durante ese período. Se analiza el concepto político de la ciudad y la pretensión de comprenderla como sistema, a través del dominio de su imagen y del control de la renovación constructiva. Se estudian los principales cambios en la configuración de la capital andaluza, con la incorporación del río en el marco urbano, la ocupación de áreas del espacio intramuros y la modesta extensión de la urbe hacia el exterior, especialmente en el contexto de la edificación de diversas arquitecturas militares y industriales. También se estudia el impacto que desde el punto de vista urbanístico tuvo la ocupación francesa en Sevilla, y el éxito de los nuevos espacios abiertos en la urbe con tal ocasión, que se convierten en ensayos de los cambios que se irán desarrollando en mayor o menor medida durante el siglo XIX.

Palabras clave: Ilustración; Sevilla; urbanismo; imagen urbana; morfología urbana; intervenciones urbanas.

ABSTRACT: This study explores urban changes that were occurred in Seville during the Age of Enlightenment. It analyses the political concept of the city and the understanding of it as a system. Consequences of these ideas were the development 
of a cartographic image of the town and a stricter control of local architecture by the city council. Several specific topics of this time are studied, as relationship between Seville and the river, the occupation of areas in the ancient city, and a modest extension of the city outwards, especially after the building of some military and industrial architectures. It also focuses on outcomes of the French occupation in the city, when some new spaces are opened in the urban shape of Seville. After this period, when Borbon monarchy is restored, the city council intends to finish some of these open spaces, some of these as a new Plaza Mayor, with the alignment of surronding streets. These attempts were not put into practice, but foreshadow changes that were later developed in the planning of the city during the nineteenth and twentieth century.

Key words: Enlightenment; Seville; Urbanism; Urban image; Urban morphology; Urban interventions.

\section{INTRODUCCIÓN}

La extensión de los ideales del siglo de las Luces, con sus profundas transformaciones sociales, políticas y mentales, supone la aproximación a muchos de los aspectos que consideramos característicos del mundo contemporáneo. Durante la segunda mitad del siglo XVIII se inicia una sucesión de cambios que anuncian o caminan hacia la participación global en el poder político, la finalidad pública de su acción, el reconocimiento paulatino del súbdito como ciudadano o la nueva organización del estado, a través del protagonismo de unas clases urbanas capaces de recibir y generar nuevas modas, gustos y criterios de tipo cultural o estético.

Sin duda, estos aspectos marcan una distinta visión sobre la ciudad donde se producen estos cambios. El desarrollo de la forma urbana, y la plasmación en una nueva arquitectura ciudadana, serán consecuentes con tales transformaciones, de acuerdo con la proyección fundamentalmente social de esas artes. En la España de la segunda mitad del XVIII los valores de la funcionalidad, la racionalidad, el orden o la homogeneidad de los elementos aparecen cada vez en mayor medida como categorías fundamentales en la definición de los espacios urbanos. Si el orden y la perspectiva se consideraban durante el Barroco al servicio de los valores simbólicos propios de la época, asociados a los lugares celebrativos propios de los fastos y la exaltación de una jerárquica organización social, ahora se convierten en elementos de un urbanismo fundamentalmente justificado por la búsqueda de la felicidad del común cuyo trasunto en la arquitectura será la aparición de una arquitectura pública, abierta a la innovación tipológica. La construcción al menos mental, de la ciudad ilustrada, se configurará en los valores de la comodidad de sus habitantes, asociada a la claridad con que es percibida mediante el orden estético de su hermosura, organizada por la política de control de la administración, 
que tutelará o auspiciará las actuaciones que se produzcan conforme al concepto de policía urbana ${ }^{1}$.

Lentamente irá surgiendo en la mente de los responsables o promotores de las intervenciones en la ciudad otra idea, nacida tanto por la determinación con que la transformación urbana se acomete como por las dificultades con que sus proyectos se desenvuelven en ese ámbito. Se trata de la aparición de una conciencia bistórica, sustentada sobre la seguridad del carácter útil y necesario de las reformas. Esa rotundidad de sus intervenciones proviene del análisis de la ciudad presente como resultado de unas condiciones generadas por el pasado, y confirma el papel trascendente de sus acciones, por cuando su destino será el disfrute de futuras generaciones de ciudadanos, receptores últimos de su dedicación moral hacia el bien público.

\section{LA CIUDAD COMO SISTEMA.}

La introducción de las ideas ilustradas y su proyección sobre la forma de la ciudad provienen, en el caso de Sevilla, de una idea de progreso para la misma que está amparada en el entendimiento de las necesarias reformas de la ciudad de modo global, de un modo que permitiera contemplar el conjunto de actuaciones como un sistema.

Las actuaciones de carácter ilustrado tendrán como prólogo la asistencia de Julián Robiou, caballero de Santiago y marqués de Piedrabuena, unido al servicio del marqués de Ensenada en su trayectoria anterior en la administración de la corona. Aunque sería solo unos meses asistente de la ciudad, en concreto de julio a noviembre de 1760, hasta su nombramiento como intendente del ejército y reino de Galicia, en su mandato se redactaría el primer proyecto de intervención para el barrio de la Laguna, en la zona intramuros de la ciudad. Sería durante la asistencia de su sustituto Ramón Larumbe (1760-1767) cuando se inicie la urbanización efectiva de esta área urbana. Durante el mandato de este último se produciría la expulsión de los jesuitas, y se restaurarían las representaciones teatrales en la capital2 En ese tiempo se asiste a la práctica conclusión de las obras de la Real Fábrica de Tabacos, a la erección de la Puerta de San Fernando y el levantamiento de la calle Real de San Carlos, actual San Fernando, entre la mencionada fábrica y la ciudad.

1. Cfr. Anguita CANTERo, Ricardo. "La concepción teórica de la idea de ciudad en la Ilustración española: la Policía urbana y los nuevos fundamentos de orden, comodidad y aspecto público". Cuadernos de arte de la Universidad de Granada, 1996, 7, pp. 105-120; vid. Ordenanza y policía urbana: los orígenes de la reglamentación edificatoria en España: (1750-1900). Granada: Universidad, 1997.

2. Aguilar Piñal, Francisco. Sevilla y el teatro en el siglo XVIII. Oviedo: Universidad, 1974; Historia de Sevilla. Siglo XVIII. Sevilla: Universidad, 1989. Robiou y La Laguna. En Ollero, F. El barrio de la Laguna de Sevilla. Diseño urbano. Razón y burguesía en el Siglo de las Luces. Sevilla: Universidad de Sevilla, 2012, nota 46. 
Son años de reconstrucción de la urbe tras el terremoto de 1755, que había afectado a gran número de edificios religiosos e institucionales y asolado una parte importante de su caserío. Por ello se procurará el cumplimiento de la Real Orden de 1754 que prohibía la construcción de casas fuera de las murallas, prosiguiendo la normativa de la ciudad con el desarrollo de estos principios, acentuando la reconstrucción de casas y la ocupación de los solares yermos intramuros, tal como se observa en la Reales Provisión del Consejo que aprueba en 1760 los acuerdos municipales tomados al efecto ${ }^{3}$.

Pero será la política urbana de Pablo de Olavide durante el ejercicio de su asistencia en Sevilla (1767-1777) la que destaca precisamente por ser la primera acción política que pretende comprometer aspectos diversos y complementarios de la ciudad para conseguir su mejora de conjunto. En palabras de Defourneaux, Olavide llegó a la capital del Sur "completamente decidido... a hacer de la gran ciudad andaluza una urbe nueva, material e intelectualmente ${ }^{4}$.

Contando con la experiencia al frente del hospicio de Madrid, Olavide actúa sobre la ciudad fundamentando lo principal de su acción en la mejora de la policía urbana, tal como manifiestan sus conocidas intervenciones para el desarrollo administrativo de un Reglamento de limpieza de octubre de 1767, o el nuevo reglamento para la Junta de Propios y Arbitrios, del año siguiente, con la que se pretendía racionalizar la administración municipal, y donde entre otras normas, se establecían los salarios, plantilla y funciones de la maestría mayor de obras en la ciudad; a Olavide le cupo la aplicación para la ciudad de Sevilla de la Real Cédula de agosto de 1769 que establecía para algunas ciudades del reino la división de su superficie en cuarteles y barrios, con precedente inmediato en la villa de Madrid y en ejemplos anteriores durante la Edad Moderna.

La actividad de Olavide no solo se redujo a estas acciones de índole tutelar o administrativa, sino que participó en proyectos o intervenciones para introducir determinadas tipologías de arquitectura pública en la ciudad, o a través de otras mejoras urbanísticas y de infraestructuras, que hemos tratado exhaustivamente en otra ocasión, y que sintetizaremos en las próximas líneas ${ }^{5}$. Una vez asentada su posición económica, su viaje por Europa entre 1757 y 1765 le permitió conocer de primera mano alguna de las reformas urbanísticas que se llevaban a cabo en las ciudades francesas de la época, como fue el caso de Lyon o París. Otro cauce para el sostén de sus reflexiones sería su excelente biblioteca, completada en los años sesenta con presencia fundamental de autores franceses como Montesquieu, Diderot, Voltaire, Rousseau, Herbert o Mirabeau, así como traducciones al francés

3. Márquez Redondo, Ana María. El ayuntamiento de Sevilla en el siglo XVIII. Sevilla: Ayuntamiento, 2010, p. 875.

4. Defourneaux, Marcelin. Pablo de Olavide, el afrancesado. (París: Presses universitaires de France, 1959). Sevilla: Padilla. Productora Andaluza de Programas, 1990, p. 190. pp. 33-56

5. Ollero Lobato, Francisco. "Olavide y las artes en Sevilla". Ilustración y Libertades, 2007, 1, 
de otros idiomas, como Maquiavelo, la Utopia de Moro, y literatura inglesa. La cercanía a las motivaciones de comodidad y beneficio del común que se alegaban para las transformaciones urbanísticas del período eran difundidas a través de la prensa internacional, suscrito como sabemos se hallaba Olavide a las gacetas de París y Ámsterdam. Otra vía de información para Don Pablo lo constituían los manuscritos explicativos contratados ex profeso para el conocimiento de determinadas operaciones, o las entrevistas personales, como las que tuvo con el cónsul español en Burdeos, Raimundo de Oñis, al que solicitó información sobre unas instalaciones para baños, pidiendo le reenviase planos y el reglamento para su uso. Su preocupación por el teatro le llevaría igualmente a indagar sobre el diseño de los edificios de esta tipología, pidiendo en 1768 al ministro del estado de Parma, Guillermo de Tillot, le remitiera el diseño de un teatro edificado recientemente en Bolonia u otro del territorio transalpino que le sirviera de modelo para el que quería levantar en Sevilla. En diciembre de 1768 hizo traer a Sevilla a Charles La Traverse para que le asesorara sobre el mencionado edificio teatral, que se levantaría finalmente en la plaza del Duque con fachada hacia la calle de las Armas, y que quedaría inconcluso tras la caída del asistente peruano.

Además del teatro, Olavide potenciaría la creación de un hospicio en el antiguo colegio jesuita de San Hermenegildo, para lo cual movió la voluntad del arzobispo y la aquiescencia del cabildo. Sin recursos económicos, el intento quedaría en suspenso, pero la idea sería retomada posteriormente por sus sucesores en el cargo Domenzain y López de Lerena. Otra propuesta de la arquitectura civil de la ciudad por la que Olavide se preocuparía sería la constitución de un gran cuartel donde integrar las tropas que se distribuían en la ciudad entre posadas y casas particulares. Para ello se propondría la conversión en alojamiento de tropas de la antigua fábrica de Tabacos, que ocupaba el espacio donde se sitúa en la actualidad la plaza del Cristo de Burgos, encargando un proyecto a los maestros de obras Ignacio Moreno y Pedro de San Martín. Este proyecto sería abandonado con el reforzamiento del mando militar en Sevilla desde 1776 y la necesidad de contar con edificios exentos y operativos de nueva planta.

Donde la actividad de Olavide se hará más evidente será sin duda en los aspectos más específicamente urbanísticos de su etapa como asistente, que mencionaremos más adelante. Desde 1767 en la creación del Barrio de la Laguna según ideas de trazado rectilíneo, con simetría y homogeneidad en sus construcciones. Para llevar a cabo el proyecto implicará en la compra del terreno y la construcción de casas a distintos amigos y colaboradores en la gestión municipal. Su visión sobre la ciudad se plantea también en las propuestas de embellecimiento y expansión de las áreas verdes perimetrales de su cerca amurallada. Así, estará presente en la aprobación de las obras del Patín de las Damas, un espacio extramuros junto a la Puerta de la Barqueta que se ordena y relaciona con el río mediante una escalinata, para cuya idea contaría con Antonio de Ulloa, autor intelectual del proyecto, y con el asesoramiento de los ingenieros Carlos Witz, José Espeliux y Charles Lemaur, este último colaborador de Ulloa en las obras de los canales de Castilla, y junto con Espelieux, 
intervinientes en el proceso de poblamiento de las Nuevas Poblaciones de Andalucía, de la que Don Pablo será mentor e intendente. En 1774 el asistente propondrá al cabildo el desarrollo de una paseo desde la alameda de San Telmo hacia la venta de Eritaña, lo que inicia la expansión paisajística hacia el sur de la ciudad hispalense. Su preocupación por el río se trasladó también al tema de la mejora de su navegabilidad, de modo que el asistente de Sevilla contactará con Espelieux para que le ayude en un proyecto de navegación por el Guadalquivir entre Córdoba y Andújar, propuesta para la que el propio Olavide redactará personalmente las instrucciones del trabajo de este ingeniero.

Olavide promoverá la obtención de la primera cartografía global de la ciudad, al menos entre las que conocemos hoy día, la imagen gráfica de una urbe sobre la que sorprende la ausencia hasta fechas tan tardías de un plano general, en una población que representara al Estado durante tantos años como puerto atlántico hacia América. Concebir su imagen significaba introducir un elemento de diagnóstico de los problemas urbanos, pero también posibilitaba el dominio de la misma a través de la obtención de su apariencia, pues en palabras del propio asistente, siendo ciudad tan poblada y extensa «...siendo difícil comprenderla, era mucho más difícil gobernarla ". Con la referencia de los ejemplos que se habían realizado para Madrid durante el reinado carolino, encargó en 1771 la realización del plano de Sevilla a Francisco Manuel Coelho, protegido posteriormente del propio asistente en la planificación de las Nuevas Poblaciones. Tras la elaboración del mismo, este fue mandado grabar en cobre y tirar en Madrid, aunque fue finalmente estampado por el artífice José Braulio Amat. El encargo de Olavide sería premiado más tarde por la Academia de San Fernando madrileña (fig. 1).

Los resultados de la acción de Olavide en la ciudad estarían entorpecidos por varios factores. El primero de ellos, la intensa actividad del personaje, que dedicó la mayor parte de su tiempo en el desempeño y organización de la intendencia de las Nuevas Poblaciones de Andalucía, ocupación que obligaba al protagonista a largas ausencias en la capital del Betis. Además, la formación intelectual de Olavide,

6. Carta de Olavide a Aranda fechada en 23 de septiembre de 1771 y transcrita por ALGARín VÉLEZ, Ignacio. Método de transcripción y restitución planimétrica. Su aplicación al estudio del plano de Sevilla de 1771 mandado levantar por disposición del Sr. D. Pablo de Olavide, asistente de esta ciudad. Sevilla: Focus-Abengoa, 2000, p. 39. Sobre Olavide y sus ideas urbanísticas sobre Sevilla se citarán en el presente trabajo varias publicaciones, de las que destacamos ahora Aguilar PIÑal, Francisco. $L a$ Sevilla de Olavide (1767-1778). Sevilla, 1966, y "Un paseo por la Sevilla de Olavide». En Historia del Urbanismo Sevillano. Sevilla: Real Academia de Bellas Artes de Santa Isabel de Hungría, 1972, pp. 107-131; MATTOS-CÁRDENAS, Leonardo. "Olavide y el urbanismo». En La influencia andaluza en los núcleos urbanos americanos: Actas de las VII Jornadas de Andalucía y América. 1990, pp. 109-134; Ollero Lobato, Francisco. "Olavide y las artes en Sevilla". En Ilustración y Libertades, 2007, n. ${ }^{\circ}$, pp. 33-56, además de las datos presentes en las biografías de Defourneaux, de Perdices Blas, Luis. Pablo de Olavide (1725-1803) el ilustrado. Madrid: Universidad Complutense, 1993, y de MARCHENA, Juan. El tiempo ilustrado de Pablo de Olavide. Vida, obra y sueños de un americano en la España del siglo XVIII. Sevilla: Alfar, 2001. 


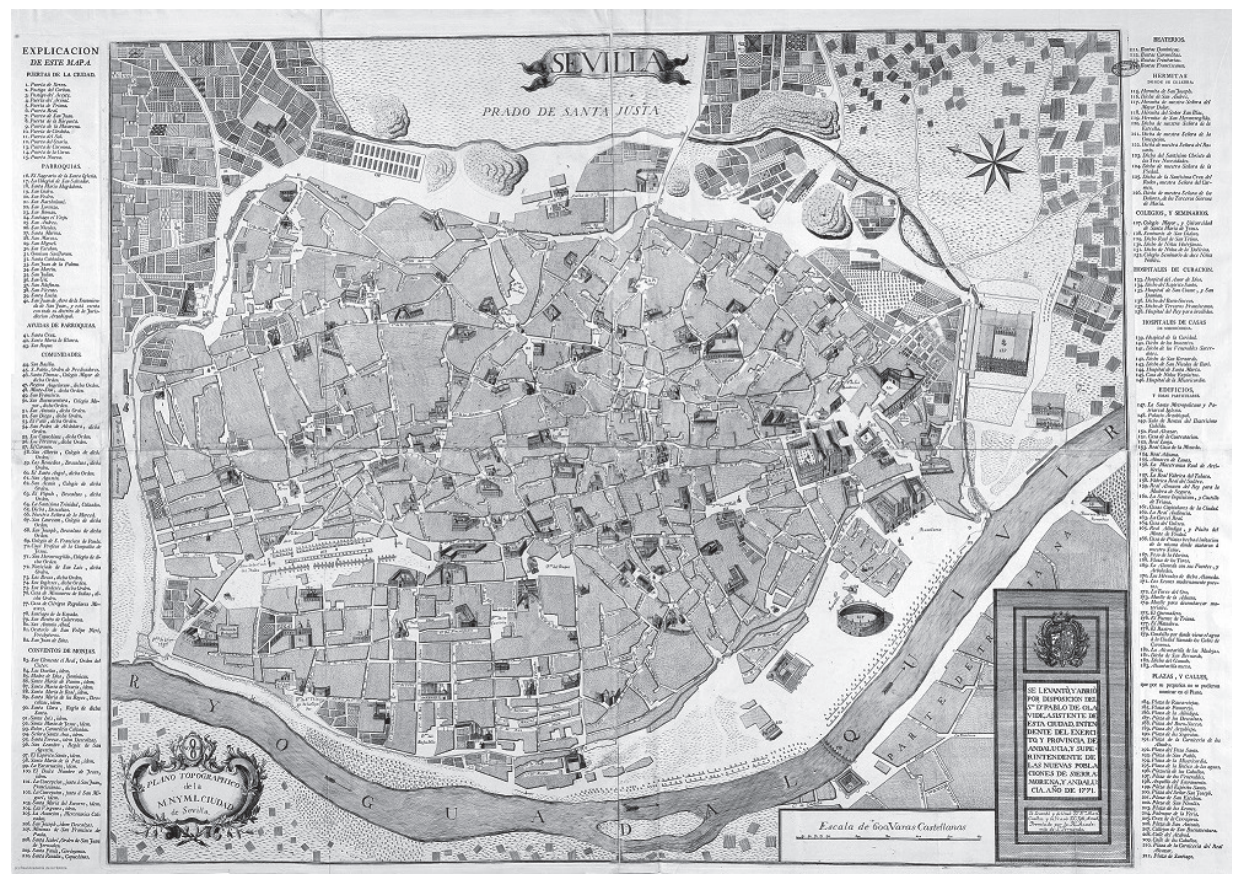

Figura 1. Plano topográfico de la Ciudad de Sevilla,

dibujado por Francisco Manuel Coelho, grabado por José Amat. 1771.

más operativa y práctica que intensa en relación con los temas de carácter urbano y arquitectónico, limitaba la consecución de sus aspiraciones. Finalmente, tal como ya destacase Suárez Garmendia, la ausencia en la capital de arquitectos académicos que pudieran ordenar sus realizaciones conforme al control del diseño y la actividad profesional, déficit más acusado aún en las décadas siguientes cuando el dominio intelectual y ejecutivo de la Academia se fuera haciendo más efectivo gracias al apoyo que al organismo otorga la legislación emitida al efecto.

Tras Olavide, el concepto de la reforma global y sistemática de la ciudad, permanece en la mente de los rectores de la administración municipal, y se pone de manifiesto en los momentos en que se hace evidente la necesidad de modificar las acciones y características de la construcción en la urbe. La trayectoria de gobierno en Sevilla, pese al auto contra el peruano, sería de continuidad con la asistencia de Francisco Domenzain (1778-1783), hombre de confianza que fuera de Olavide y participante en su famosa tertulia. El afán de evidenciar el espíritu de las reformas en la ciudad queda patente en la asistencia de López de Lerena (1783-1785), 
cuando se refleja en el nuevo plano de la ciudad, realizado por Tomás López en 1788, la enumeración de las obras de mejora acometidas tras la riada de $1783^{7}$.

La necesidad de afrontar una reforma global en la ciudad se evidencia en el cabildo municipal en 1784, cuando en la institución se discute la elección de un nuevo maestro mayor de obras de Sevilla. En la crítica al anterior ocupante del cargo, de formación tradicional, se reconocía su honradez y laboriosidad, pero también el hecho de que

Estos hombres... carecen de muchos conocimientos, y de aquella extensión de ideas, capaz de abrazar un plan general de reforma, y de llevar al fin bajo un sistema constante, y seguido la execusión de un proyecto de seguridad, hermosura y comodidad qual lo requería Sevilla ${ }^{8}$.

Así pues, el entendimiento de la población como sistema, en la conciencia de la utilidad de ese proyecto de seguridad, hermosura y comodidad, se sitúa en el centro mismo de la definición de ciudad ilustrada, y este plan para la urbe, asî como su plasmación gráfica detallada, continuará siendo aspiración no resuelta en los primeros años del nuevo siglo. Por ejemplo, en 1820 será el síndico segundo del ayuntamiento liberal el que manifiesta las dificultades para obtener las medidas de las nuevas casas que se construyen "por falta de un plano general de la ciudad" por lo que solicita se nombre un Arquitecto "para hacer el dicho plano y demás desempeño de sus obligaciones»?

7. Extracto de la Nota del Plano Geométrico de la Ciudad de Sevilla, realizado por Tomás López de Vargas y Churruca en 1788. "A este plano se le ha aumentado el Barrio de Triana y las obras nuevas que son las siguientes: $1 .{ }^{a}$ Un malecón desde la muralla del Blanquillo al Hospital de la Sangre, hecho con tierra y calibres, que no se manifiesta en este plano por no alcanzar la comprehensión de su escala. 2. ${ }^{\text {a }}$ Reedificación de la muralla que estaba arruinada desde la Puerta de San Juan a la de de Colon. 3. ${ }^{\mathrm{a}}$ Alamedas y malecones de piedra, señalados con la letra A, desde el Almacén del Rey a la torre del Lorito, con asientos en toda su extensión, y cinco entradas o salidas para el paso del público, anotadas con $\mathrm{B}$, executadas con piedra de sal y pez con sus alebrices y tablones, para en tiempo de las avenidas del río. 4. ${ }^{a}$ El puente Nuevo $\mathrm{C}$ que da paso al barrio de Triana el que se halla con prevenciones dobles, para su resguardo que antes no tenía. $5 .^{a}$ El primoroso puente D, llamado el Tagarete, que da paso al sitio de la Torre del Loro".

8. Informe del procurador mayor Joaquín de Goyeneta, fechado el 9 de septiembre de 1795 , relatando la actuación del cabildo sobre estos asuntos en años anteriores. (Archivo Municipal de Sevilla. Sección V. Escribanía de cabildo. Siglo XVIII. Tomo 25, n. ${ }^{\circ}$ 21. Informe de Joaquín Goyeneta del 9 de septiembre de 1797. Fol. 24-30v, en concreto 24v). Transcrito por Ollero LOBATO, F. Cultura artística y arquitectura en la Sevilla de la Ilustración (1775-1808). Sevilla: Caja de Ahorros San Fernando, 2004, p. 195. Sobre esta nomenclatura gira sin duda el influjo del Plan General de Madrid de Juan Francisco González, expuesto en 1766. Cfr. SAmBricio, C. «Vivienda y crecimiento urbano en el Madrid de Carlos III». En Carlos III, Alcalde de Madrid, 1788-1988. Madrid: Ayuntamiento, 1988, pp. 381-448. (1r)

9. AMS. Sec. IX. Escribanía de cabildo. Siglo XIX. 2. ${ }^{a}$ Época Constitucional. Tomo 2. Exp. 71. 


\section{MEDIOS DE INTERVENCIÓN}

Por esos años, la inquietud ilustrada por el control del diseño arquitectónico, así como la pretensión de una centralización institucional del mismo, llevó en Sevilla a un cambio sustancial en el modo de intervención sobre su trama urbana. Durante el Barroco ya existía una política preocupada por el desarrollo de rectificaciones puntuales del trazado, por cuanto la edificación de nuevas viviendas en su caserío exigía el proceso de la dación de medidas, mediante el cual, a través de la medición de las áreas superficiales y del atirantado de las líneas de las nuevas fachadas que fueran a edificarse, se pretendía tanto garantizar el mantenimiento del espacio público del común, como la recta alienación de la acera de calle sujeta a la obra. Para ello se establecía un peculiar consenso en el que participaban tanto el municipio, -con la presencia del maestro mayor de obras y un delegado de la autoridad municipal-, como el gremio de albañiles, con la asistencia de sus cargos, así como el propio maestro de obras elegido por la propiedad para la construcción. A efectos prácticos, tal actividad conducía a una lenta y modesta rectificación paulatina del irregular trazado de su callejero.

Durante el período ilustrado, tal proceder experimento una notable transformación. Mediante el influjo de las ordenanzas municipales, especialmente las establecidas en la villa de Madrid, comenzó en el seno del cabildo municipal en 1779 un debate que daría lugar a la obligación, por parte de los maestros de obras, de presentar sus diseños y trazas al arquitecto municipal, que era el responsable de verificar que sus proyectos quedaban "con arreglo al arte» y a la policía urbana mediante la emisión de una licencia de obras. Además, estos cambios significarían la limitación de autonomía que sobre el asunto mostraban los gremios de la construcción, de modo que se desterraría primero del acto de la dación de medidas a los maestros carpinteros de los blanco, y más tarde se sujetaría a la autoridad municipal la participación de los propios representantes del gremio de albañilería de la ciudad. Estas licencias de obras aparecerán desde 1789, y se generalizan como acto recurrente en las nuevas intervenciones sobre la arquitectura civil desde 1801. La extensión de las competencias de los maestros mayores del cabildo, cuyas funciones habían sido ya reguladas desde la nueva normativa de propios y arbitrios de Olavide, se explican mediante esta tendencia hacia la centralización artística fomentada por la Academia.

Estas modificaciones tendrán como objeto una mayor homogeneidad formal en los alzados de las casas sevillanas, y desde el punto de vista urbanístico una extensión de la escala en la transformación del viario, al menos en algunos aspectos como los de la eliminación de ángulos y angosturas en algunas de las calles, o en la privatización de los adarves, con la compra de ese suelo público por parte de los propietarios se levantan nuevas edificaciones o amplían las ya existentes. Estas intervenciones, más cotidianas y mayoritarias, se combinaron con el acatamiento de Reales Provisiones y Cédulas que obligaban al cumplimiento de reformas o intervenciones de carácter general en el entendimiento de la ciudad ilustrada, 
o con la aprobación por el Consejo de Castilla de proyectos más específicos, como el que autorizaría la urbanización en curso del barrio de la Laguna en 1769.

La segunda acción del municipio para impulsar la existencia de ese plan general y la obtención de resultados en la ciudad sería favorecer la elección de un arquitecto de formación o al menos inspiración académica que pudiera hacerse cargo de tal misión. En 1784 Félix Caraza, un constructor de formación gaditana, recibiría el nombramiento de arquitecto mayor del municipio, un título novedoso para el responsable de la arquitectura de la ciudad, al que ayudaría en su elección la forja de un plan general de reformas para la mejora de la navegación del río Guadalquivir. En 1786 se vio obligado a renunciar al cargo, al tener que descender a la posición de maestro de obras, puesto que se le denuncia por no estar titulado o aprobado por la Academia de San Fernando. El cargo sería ocupado de manera interina por el maestro local José Echamorro, quien pleitearía primero con Caraza y luego con el arquitecto jerezano Cayetano Vélez desde que este fuese nombrado titular del municipio en 1809.

Estos conflictos entre los responsables de la arquitectura de la ciudad, y el hecho de que ninguno de ellos fuese aprobado por la Academia, al menos hasta que Vélez consiguiera un reconocimiento oficial en este sentido en 1818, dificultaría el desarrollo de un plan de actuación sobre la ciudad, unido al hecho de que la Comisión de Arquitectura de la Academia de San Fernando, que había desarrollado su control sobre el diseño arquitectónico en todo el reino desde las disposiciones de los años setenta, no aprobaría aquellos enviados desde Sevilla en los años finales del siglo. Habría que esperar nada menos que al nombramiento de Melchor Cano en la ciudad en 1826 para que al frente de sus competencias en arquitectura se encontrara un arquitecto aprobado por la Academia ${ }^{10}$.

\section{CULTURA ARQUiTECTÓNICA Y CIUDAD}

La presencia en Sevilla de importantes ingenieros militares españoles y extranjeros -entre los segundos Jean Maritz, destinado a las obras de la Real Fundición de Artillería, o Sebastián Van der Borcht, en el imponente edificio de la Real Fábrica de Tabacos-, constituyeron un ejemplo de formación técnica y matemática en el oficio de la construcción, así como un obrador para los arquitectos locales, que participarían en mayor o menor medida en las labores de finalización de estos edificios. En sus curricula estos alarifes expondrían con orgullo su pasado como constructores al servicio de estos ingenieros, militares al servicio de la corona que dinamizarían el panorama de la segunda mitad del siglo con su participación en

10. SuÁREZ GARMENDIA, José Manuel. Arquitectura y Urbanismo en la Sevilla del siglo XIX. Sevilla: Diputación, 1986; SAMBricio, Carlos. La Arquitectura española de la Ilustración. Madrid: Instituto Nacional de Administración Pública, 1986, que recoge diversos datos sobre la evaluación de proyectos por la Comisión de Arquitectura. Ollero LoBAto, Francisco. Cultura artística y arquitectura... Op. cit. 
las academias locales, o la redacción de tratados de fortificaciones o aritmética. Ese sería el caso del propio Van der Bocht, autor de un Tratado general de la guerra; otros escritos de este género de literatura erudita se llegarían a publicar en la ciudad, como el texto del oficial de la Armada Layburu y Azagra, o del profesor de matemáticas del colegio de San Telmo Vázquez Tinoco, autor de un Tratado de fortificación con los Pareceres de los Autores más celebrados... que explican el aprecio de la ciencia local por este género científico. En cualquier caso, en la literatura ingenieril de la época, como en el caso de la adaptación española de la obra de John Muller por Miguel Sánchez Taramas, el Tratado de Fortificación..., publicado en Barcelona en 1769, aparecen preferencias por determinadas tramas para el diseño de la ciudad, como es el caso del modelo ortogonal propuesto en la obra del militar inglés, que ahondarían en una noción apropiada para la urbe moderna ${ }^{11}$.

La estancia de estos ingenieros en la ciudad contribuyó a la conformación de un ambiente cultural propicio a una aproximación más cientifista a los problemas de la construcción, y a una comprensión favorable a los diseños propuestos para la inserción de estas fábricas en la ciudad. Sería responsabilidad directa del mencionado Van der Bocht la realización de la calle de San Carlos, actual San Fernando, en el contexto de la adecuación urbana del nuevo edificio de la Real Fábrica de Tabacos en la ciudad. Esta operación, como otras nuevas vías como la existente entre los edificios de la Real Fábrica de Salitre, serán elogiados por la literatura descriptiva coetánea que se imprime en la ciudad por esos años, manifestando el estímulo hacia el diseño rectilíneo y la estética de la homogeneidad en la población. Así, Arana de Valflora habla de la calle de San Carlos como una "hermosa y recta calle» rematada en la nueva Puerta de San Fernando, mientras que la situada en la Real Fábrica de Salitre, que empezaba en el Convento de la trinidad y acababa a mediados de las distancia hasta la Puerta Osario, era adjetivada en similares términos ${ }^{12}$.

Sin duda fue importante en la extensión de una cultura renovada de la ciudad la presencia en la misma de buena parte de los miembros de la elite ilustrada, que acompañaron en la tertulia y los afanes reformistas al mencionado Olavide, alguno de ellos tan señalados en el panorama nacional de las ciencias y letras como Antonio Capmany, que casó en la ciudad en 1769 y luego participaría con sus

11. CAPEL, Horacio et al. De palas a Minerva. La formación científica y la estructura institucional de los ingenieros militares en el siglo XVIII. Barcelona: Serbal. CSIC, 1988, o LEón TELLO, Francisco y SANZ SANZ, Virginia. Estética y teoría de la arquitectura en los tratados españoles del siglo XVIII. Madrid: CSIC, 1994; RABANAL Yus, Aurora. "El concepto de ciudad en los tratados de arquitectura militar y fortificación en el siglo XVIII en España». Anales del Instituto de Investigaciones Estéticas, 2002, 24/81, pp. 33-52; PITA GonZÁLEZ, María Soledad. Referencias a la arquitectura civil en tratados de fortificación de los siglos XVI al XVIII. Madrid: Cultiva Libros, 2009.

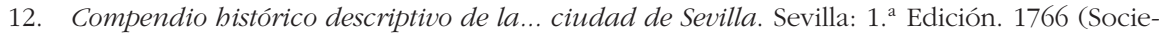
dad de bibliófilos andaluces, 1978), pp. 19 y 86. 
escritos en su vida cultural, Jovellanos, Alcalde del Crimen de la Real Audiencia desde 1768 a 1778, o, ya más tarde, Juan Pablo Forner desde 1790, que incentivarían el espíritu de la reforma general de la sociedad española en la población sevillana. Su influjo sobre la aristocracia local se desarrolla a través de lecturas comunes y las relaciones personales establecidas, y aunque no estuviera en el centro de sus inquietudes una idea específica de la urbe o de sus repercusiones en el campo del diseño urbano, si puede deducirse el influjo de un planteamiento estético favorable a "la unidad entre las partes, la noble sencillez o ausencia de adornos innecesarios, la tranquila grandeza, la majestad, el orden, la proporción y la simetría» ${ }^{13}$. En particular fue esencial la labor de los eruditos que conformarían el corpus de un inventario de las artes en la ciudad: Antonio Ponz elevaría en el tomo IX de su Viage de España y en otros diversas opiniones sobre la urbe sevillana, siendo ayudado en la recopilación de datos por sevillanos ilustres como el Conde del Águila, con quien consta una interesante correspondencia. Sería en la biblioteca de este último donde tendrían cabida libros de interés en la divulgación de un nuevo pensamiento en relación con las artes, como el Elogio a las Bellas Artes, de Jovellanos ${ }^{14}$. Las opiniones sobre la ciudad vertidas en el Viage... tendrán una polémica repercusión en el panorama sevillano, entre los que asentían a las críticas o juicios del levantino sobre las características de la urbey aquellos que echaban en falta en la obra del clérigo un mayor tono laudatorio. Su planteamiento sobre la ciudad enjuiciaba como veremos más adelante su trama general, el fomento de la policía urbana, así como el desarrollo del ensanche de las calles y la simetría vial. En Sevilla valoraba especialmente los paseos de la población, algunos en proceso de transformación como el del Arenal y su prolongación a Bellaflor, donde estimaba el abate que los sevillanos no tenían que envidiar al Prado de Madrid ${ }^{15}$.

Por su parte, Ceán Bermúdez, en sus diferentes estancias en Sevilla, desde su llegada a la misma en 1767 como secretario de Jovellanos, tendrá un papel

13. Como se indica para el caso de Jovellanos en SAmaniego Burgos, José A. "Jovellanos y las Bellas Artes». Cuadernos de investigación, 2010-2011, 4-5, pp. 313-356.

14. Aguilar Piñal, Francisco. "Una biblioteca dieciochesca: la sevillana del Conde del Aguila». Cuadernos Bibliográficos, 1978, 37, pp. 1-21.

15. Sobre Ponz y Sevilla, $C f r$. Juan de Mata CARriazo. "Correspondencia de D. Antonio Ponz, con el Conde del Aguila", Archivo Español de Arte y Arqueología, 1929, 14, pp. 157-183; Puente, Joaquín de la. La visión de la realidad española en los viajes de Don Antonio Ponz. Madrid: Moneda y crédito, 1968; Crespo Delgado, Daniel. Un viaje para la Ilustración. El viaje de España (1772-1794) de Antonio Ponz. Madrid: Marcial Pons, 2012. Para las repercusiones de la obra de Ponz en la ciudad, véase Gómez PIÑol, Emilio. "Entre la norma y la fantasía: la obra de Jerónimo Balbás en España y México». Temas de Estética y Arte, 1988, 2, pp. 97-136; SERrERA, Juan Miguel. "Los ideales neoclásicos y la destrucción del barroco. Ceán Bermúdez y Jerónimo Balbas», Archivo Hispalense, 1990, 223, pp. 135-160; Ollero, Cultura artística y arquitectura..., Op. cit. La referencia a los paseos de Sevilla citada por LEÓN TELLO, Francisco y SANZ SANZ, Virginia. Estética y teoría de la Arquitectura en los tratados españoles del siglo XVIII. Madrid: CSIC, 1994, p. 1266. 
interesante en la configuración del panorama de la crítica y la historiografía artística de la ciudad. En sus primeros años de residencia, participará de la inquietud del siglo por la institucionalización de una academia de artes, aprendiendo pintura de la mano de Juan de Espinal. En su estancia en la ciudad en los años setenta del siglo, gracias a la adquisición de un ejemplar en la reputada librería Berard de la capital hispalense, y a través del presbítero Juan Álvarez, conocerá la obra de Milizia Arte di Videre... que acabará traduciendo al castellano. Junto a su trabajo de documentación para la edición del Diccionario Histórico de las más ilustres profesores de las Bellas Artes en España (1800) y la ampliación de la obra de Llaguno Noticias de los Arquitectos y Arquitectura en España... que vería finalmente la luz en 1829, Ceán publicará en 1804 una monografía sobre la catedral hispalense, de honda repercusión en la posterior literatura artística de la ciudad. Ceán apoyará la labor de Francisco de Bruna al frente de la Real Escuela sevillana de Nobles Artes, y pese a su impresión negativa sobre el camino de estas disciplinas en la urbe andaluza, basada en la poca capacidad de los integrantes de la citada Escuela y sobre todo en la ausencia de arquitectos académicos en la misma, no dejará de participar en proyectos de promoción de la reforma artística. Ese será el caso del diseño de retablos, como el que ideará para los Servitas de Fuentes de Andalucía, o en su opinión sobre el estado de las artes, Itálica o el nombramiento de un director conservador para la excavación, informe que elevaría a petición de la Academia de San Fernando en $1817^{16}$.

La reforma específica de las artes en la ciudad se concretaría en la conformación de la Real Escuela de las Tres Nobles Artes, de carácter oficial desde 1775. Su mentor, el oidor Francisco de Bruna, coleccionista y aficionado, tendría un papel tan destacado en su desarrollo como para redactar sus estatutos, bajo el influjo de San Carlos de Valencia y San Fernando de Madrid. Apoyado por el Conde de Floridablanca y Antonio Ponz, su labor difusora de la necesidad de un cambio artístico en la ciudad será importante, a través de las publicaciones de las Oraciones... redactadas por Bruna para conmemorar cada ciclo docente de la institución, la exposición pública de antigüedades y obras académicas en los Reales Alcázares, o

16. Sánchez Cantón, F. J. «En el centenario de Ceán Bermúdez». Academia, 2, 1951, pp. 89-113; Romero TAllafigo, Manuel. "La fundación del Archivo General de Indias: fasto en la historia archivística europea». Archivo Hispalense. 207-208. 1985; LlEÓ CAÑAL, Vicente. "Estudio preliminar» de La descripción artística de la catedral de Sevilla. Sevilla: 1804 (Sevilla: Renacimiento, 1981); Clisson Aldama, José. Juan Agustín Ceán Bermúdez, escritor y crítico de Bellas Artes. Oviedo: Instituto de Estudios Asturianos, 1982; Wert OrtegA, Juan Pablo. "Jovellanos "aficionado". Su actividad coleccionista en relación con el origen de la moderna cultura artística". En Patronos, promotores, mecenas y clientes. Actas del VII Congreso Español de Historia del Arte. Murcia: Universidad, 1988, pp. 571-579; Ollero LoBATO, F, y Quiles García, Fernando. "La teoría arquitectónica de Ceán Bermúdez y su plasmación en una obra inédita”. Goya, 1991, 223-224, pp. 26-34; SANTiago PÁEz, Elena, El gabinete de Ceán Bermúdez. Dibujos, estampas y manuscritos de la Biblioteca Nacional. Gijón: Museo-Casa Natal de Jovellanos, 1997; Ollero, F. Cultura artística y arquitectura... Op. cit.; y "Ceán Bermúdez, Itálica y las artes en Sevilla». Academia, 2008, 106-107, pp. 49-64. 
la participación como alumnos de la Escuela tanto de artistas como de aficionados a las artes. Su papel, sin embargo, para una reforma en profundidad del panorama artístico y en particular de la arquitectura se vio muy limitado por la formación aún gremial y barroca de los integrantes de su profesorado, la preponderancia de la plástica en la formación del centro y por la ausencia de un poder coactivo efectivo de esta institución local sobre las otras responsables del patrocinio arquitectónico en la ciudad. Los exiguos fondos de la biblioteca de la Academia se dotarían, sin embargo, con algunos ejemplares interesantes para la comprensión de la ciudad en relación con el pasado grecorromano, como con la adquisición del Admirandam Romanorum antiquitatum ac veteris sculturae vestigia, de Bellori, publicado en Roma en 1693, fundamento de la anticuaria preilustrada, o la compra de 20 ejemplares de los Diez libros de Architectura... del Vitrubio de José Ortiz y Sanz (Madrid, Imprenta Real, 1787) para la docencia en el centro, adquiridos a los libreros sevillanos Berard y Cía, nutrido con láminas para el diseño de una arquitectura clasicista al servicio de la urbe ${ }^{17}$. Indudablemente, junto al conocimiento paulatino de la literatura anticuaria o aquella promovida por la Academia madrileña, cabe también entender como fundamento de una idea de la ciudad el peso de los tratadística tradicional, con la definición de modelos regulares y principios estéticos bajo las categorías y descripciones de Vitrubio, y las presencia identificada en informes e inventarios de Scamozzi, Vignola y Serlio, entre los autores italianos, y entre los españoles, el muy utilizado Arte y Uso de la Arquitectura de Fray Lorenzo de San Nicolás, y el Compendio Matemático... del Padre Tosca. Para los protagonistas más eruditos de la construcción en España, estas obras seguían siendo en la segunda mitad del XVIII las lecturas más utilizadas ${ }^{18}$.

Esos textos adquiridos o leídos en las bibliotecas públicas o privadas de la ciudad supondrían además una aportación iconográfica y literaria, que ayudaría a la comprensión de la ciudad como una Nueva Roma, apoyada expresamente en su reconocimiento como población romana, la Colonia Iulia Romula Hispalis, en el contexto de una resurrección de los estudios anticuarios y epigráficos, tal como atestiguan los temas de las disertaciones de la Real Academia de Buenas Letras ${ }^{19}$.

17. Ollero. Cultura artística... Op. cit. Sobre la Real Escuela en el XVIII, véase además Muro ORejón, Antonio. Apuntes para la bistoria de la Academia de Bellas Artes de Sevilla. Sevilla: Imprenta Provincial, 1961; Romero Murube, Joaquín. Francisco de Bruna y Abumada. Sevilla: Ayuntamiento, 1965 (Reed. Facsímil. Colegio Oficial de Aparejadores y Arquitectos Técnicos, 1997); CabeZAS García, Álvaro. Gusto orientado y fiesta pública en Sevilla. Análisis de documentos para la comprensión de la historia artística del siglo XVIII. Sevilla: Estípite, 2012.

18. Una síntesis del panorama español en Crespo Delgado, Daniel. "Lecturas y lectores en la España de la Ilustración: el caso de la literatura artística». Cuadernos de Historia Moderna, 2007, 32, pp. 31-60. El caso sevillano en Ollero, F. «La condición social y la formación intelectual de los maestros de obras del barroco: el gremio de albañilería de Sevilla a mediados del siglo XVIII». En ArANDA, Ana et al. (Dir.). Barroco Iberoamericano. Territorio, Arte, Espacio y Sociedad. Sevilla: I, pp. 163-174.

19. Aguilar Piñal, F. La Real Academia sevillana de Buenas Letras en el siglo XVIII. Madrid: CSIC, 1966. 
La expresión arquitectónica de esta identificación con el pasado antiguo se plasmará en el uso de elementos constructivos apropiados y lienzos escritos en latín o castellano, que se sitúan en los nuevos paseos y espacios ajardinados, y también en los edificios renovados al servicio del común. Con ello se publicitará la relación de la urbe con su historia antigua, y la misión favorable a la comodidad y felicidad del público con que tales obras serían realizadas ${ }^{20}$.

\section{NueVOS EJES y PERSPECTIVAS. El RÍO, LOS PASEOS Y LA CATEDRAL}

Durante la segunda mitad del siglo XVIII la ciudad asistirá a la extensión de sus espacios públicos, de acuerdo con la idea de beneficiar al común que caracteriza la proyección urbana ilustrada. Se trataba de domesticar en la medida de lo posible la naturaleza para fomentar su aprovechamiento, a la vez que se craban nuevas extensiones verdes dedicadas al recreo o la relfexión erudita. Asímismo, se sugerirán nuevos ejes, recorridos y perspectivas visuales, tanto en las intervenciones en el perímetro exterior como alrededor de la catedral, el monumento que se entendía más significativo de su casco urbano.

Un tema esencial en estas intervenciones fue el río Guadalquivir, aliado de la ciudad para su fortuna material, pero también poderoso tirano cuando su desbordamiento anegaba sus riberas y paralizaba la vida ciudadana. El problema del río dio lugar a una extensa literatura donde intervienen matemáticos, ingenieros o arquitectos, en la mayor parte de los casos escritos estos de carácter especulativo o utópico, pocas veces práctico, como el proyecto promocionado por Olavide para restaurar la navegación hasta la propia ciudad de Córdoba mediante la creación de esclusas y la eliminación de azudas ${ }^{21}$. La realización más importante del

20. Así, Matute señala las situadas en 1787 en la obra de los habitáculos de guardia del puente de barcas, o las dispuestas en el paseo de Bellaflor y compuestas por Fray Pedro Garrido, que proclamaban en uno de los pirámides de la platea central del paseo que era una obra realizada para "FELICITATI PUBLICAE POPULI HISPALENSIS». (Continuaba NATIVITATIS XPTI. M.DCC.LXXXVII.// IMPERII REGIS NRI. CAROLI III. AN. XXVIII// D.D. URBIS.// FONTEM, SCATURIENTEM,// ET VIAM. ARBORIBUS CONSITAM// IRRIGANTEM,// POSUERUNT// FRANCISCO MANSO. MARCHIONE DE RIBAS// CURANTE. En otro hito frente al anterior se dispuso el texto en castellano, que decía «En el año del nacimiento de Christo 1787//, y el 28 del reynado de Nro. rey católico// el S. D. Carlos tercero// para felicidad pública del pueblo// de Sevilla, se puso esta fuente,// cuyas aguas regasen los árboles// de este paseo de Bellaflor,// siendo asistente el Señor Don Joseph Abalos// y diputado el Señor 24 Don Fco. Manso// Marqués de Ribas", MatuTe, Justino. Anales eclesiásticos y seculares de la ciudad de Sevilla. Sevilla: Imp. E. Rasco, 1887. Tomo III, Año 1787.

21. MORAl ITUARTE, Leandro del. La obra hidraúlica en la cuenca baja del Guadalquivir (Siglos XVIII-XX). Gestión del agua y organización del territorio. Sevilla: Universidad de Sevilla. Consejería de Obras Públicas y Transportes. Ministerio de Agricultura, Pesca y Alimentación, 1991; Aguilar PIÑAL, Francisco. "Antonio de Ulloa y Sevilla». En LosadA, M. y VARELA, C. (eds.). Actas del II Centenario de Don Antonio de Ulloa. Sevilla: Escuela de Estudios Hispano-Americanos CSIC, 1995, pp. 45-58; Espín, Ángela, y DEL MORAL, Leandro. «Utopía e impotencia: La intervención de Olavide en el Guadalquivir». 
siglo será la llamada Corta de la Merlina, con la supresión de uno de los meandros más sinuosos de su curso bajo, proyecto que llevará a cabo el ingeniero italiano Scipión Perosini entre 1794 y 1796.

El otro gran tema fluvial será el de la eliminación o disminución de las riadas y el efecto erosivo del río, para la cual se fueron realizando operaciones de alcance desigual. Entre las más importantes, que pretendían además la regularización del cauce y la búsqueda de nuevos espacios para el ocio ciudadano, sería la reforma del llamado Patín de las Damas, junto a la Puerta de la Barqueta, auspiciado por Olavide, y aprobado por el cabildo de la ciudad en 1773. A la misión estructural de evitar el desgaste de sus orillas, se unía la posibilidad de desarrollar una explanada pública para el ocio, abierta con una escalinata hacia el propio río. El proyecto inicial, desarrollado por Pedro de San Martín, su hijo Vicente y José Martínez de Aponte, contaría posteriormente con el asesoramiento técnico de Antonio de Ulloa; la obra sería dirigida por Vicente de San Martín hasta 1779, fecha en que lo sustituye al frente de la misma Lucas Cintora, y sería finalizada al año siguiente con un costo final cercano a los tres millones de reales.

Otro gran esfuerzo fue el plan general de reformas desarrollado en 1784 por el arquitecto municipal Félix Caraza, que pretendía reforzar las defensas de la ciudad frente al río en varios puntos destacados de su geografía, y que tenía sus precedentes culturales en la literatura hidraúlica y en la experiencia en el efecto de las riadas del año anterior. Así, el proyecto auspiciaba la construcción de una muralla desde los almacenes de Segura aguas abajo hasta la desembocadura del Tagarete y San Telmo, para luego desviarse con el curso del Tagarete mediante un lienzo paralelo al de la propia ciudad para enlazar con el mismo a la altura de la Puerta de Córdoba. El plan preveía además una serie de defensas independientes para los arrabales, como es el caso de un murallón con el que protegería la orilla del barrio de Triana. De la importancia de estas operaciones nos habla el hecho de que quedasen reflejadas en la obra gráfica del Plano de la ciudad de Tomás López de Vargas y Machuca de 1788, dedicado al asistente López de Llerena, describiéndose algunas acciones en la propia leyenda del mismo.

La dotación para estas obras quedaría interrumpida en 1788, pero para esas fechas se habían iniciado las dos intervenciones paralelas en las márgenes del río: en la banda de Sevilla se construiría un doble murallón de piedra, iniciado en mayo de 1784 y finalizado en febrero de 1785, con tres desniveles, uno próximo al cauce, otro para el paseo de coches, donde discurría el plantío de árboles y estaba ornamentado con caminos y asientos, y uno final para proteger el comienzo del caserío de la ciudad. Para su construcción se utilizó la piedra de la Calzada antigua del Camino de Castilleja de la Cuesta, obra emprendida bajo la asistencia de Pablo

En OJeda Rivera, Juan F. (Ed.). Ilustración, Contemporaneidad y Territorio. Sevilla: Universidad Pablo de Olavide. Consejería de Obras Públicas y Transporte, 2000, pp. 47-69. Ollero, F. Cultura artística... Op. cit. 
de Olavide con el fin de encerrar las avenidas del río más allá de Triana, evitando su desalojo natural. Por otra parte, en la banda de Triana, se comenzaría en 1787 la construcción del dique desde el Altozano en dirección hacia la actual calle Betis, concebido como un paramento dispuesto con fingida tectónica de pilastras almohadilladas. Para la obra se ancló en el río un pilotaje de maderas sobre el que se elevaba en ligera pendiente la fábrica del murallón. La obra disponía la existencia de dos muelles abiertos a través de rampas divergentes que bajaban hasta el río, uno de ellos acabado en 1794. Del éxito de la obra sería su continuación, ya en el siglo XIX, por Cayetano Vélez de la obra de defensa, con la incorporación de un zócalo en la misma orilla que defendiera al dique del desgaste de las aguas. Para fines del siglo, el murallón resguardaba la ribera desde el actual puente de Isabel II hasta la altura de la parroquial de Santa Ana (fig. 2).

Tales acciones urbanísticas tuvieron como objetivo, como comentara Del Moral Ituarte, la definitiva integración de la ciudad con su río. La culminación de este proceso podría haber sido la construcción de un puente estable sobre el Guadalquivir, retomando los proyectos presentados durante la segunda mitad del XVI por Modente y el diseño de Andrés de Oviedo para una estructura de cantería fechado en 1629. La posibilidad vendría de la mano de Silvestre Pérez, autor de un proyecto de puente de cinco arcos escarzanos "bellamente proporcionados", al decir de Ceán, diseño presentado en 1824 ante el ayuntamiento de la ciudad, y que no llegó a realizarse ${ }^{22}$.

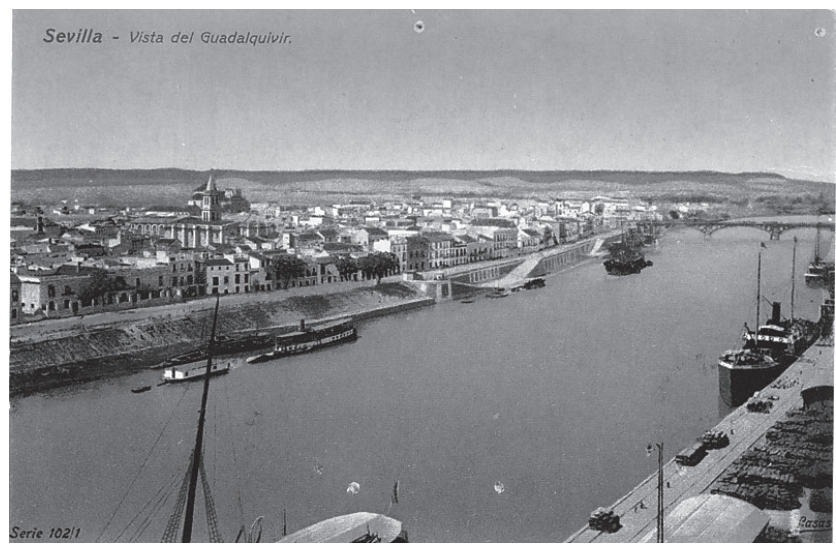

Figura 2. Vista del Guadalquivir, con la construcción del murallón en la orilla de Triana.

22. Navascués Palacios, Pedro. Arquitectura y arquitectos madrileños del siglo XIX. Madrid: Instituto de Estudios Madrileños, 1973, p. 13, y SAMBricio, Carlos. "Noticias sobre Silvestre Pérez a través de unas notas de Ceán Bermúdez». Miscelánea de Arte, 1982, pp. 220-223. Habría otros proyectos posteriores en la década de los 20-30 hasta la definitiva construcción del actual Puente de Triana, inaugurado en 1852 . 
Aunque no se llevara a la práctica la construcción de un puente estable para la comunicación de Sevilla con su principal arrabal en Triana, la construcción de muros y malecones en sus orillas supuso el reconocimiento arquitectónico de la importancia visual que se concedía al río. Esta conversión del mismo en un eje urbanístico fundamental inspiró a su vez una serie de proyectos de nuevos espacios abiertos de disposición transversal a su cauce, desarrollados durante las asistencias de José de Ávalos (1785-1793). Así, en 1786 se afronta la ampliación de la entrada al puente de barcas por la parte de Triana, y se proyecta algunos años más tarde, en 1792, la apertura de nueva plaza en el Altozano, mediante la eliminación parcial del antiguo castillo de San Jorge y la elevación en altura del terreno. En este sentido cabe interpretarse el inicio de la construcción del monumento de la Santísima Trinidad, hito urbano relacionado tipológicamente con los monumentos conmemorativos y triunfos del Barroco, y que estaba concebido a modo de linterna clásica de tres columnas dispuestas en oblicuo, sobre las cuales se pretendía instalar un grupo escultórico realizado por Blas Molner. Esta obra dotaba de significación el paseo de árboles desde el río hacia la Puerta de Triana, de modo que introducía una perspectiva visual desde el río hasta la propia ciudad. El proyecto escultórico sería definitivamente abandonado años más tarde, y su huella material desaparecería finalmente con la revolución de 1868. Sobre estas modestas intervenciones que se alimentan de la perspectiva del Guadalquivir se aprecia el conocimiento de otras acciones urbanísticas de mayor calado desarrolladas en países europeos, especialmente las ya citadas para las ciudades francesas como Lyon, ciudad que regularizara sus riberas y su extensión desde 1740, o de Burdeos, que experimenta importaciones reformas abiertas al cauce del Garona desde la primera mitad del siglo, transformaciones sobre las que hemos dado constancia del interés del propio Pablo de Olavide.

También relacionado con el río es el tema urbanístico de los paseos, con que se rodea con un cinturón verde buena parte de su casco histórico. Se trata de la plasmación urbanística de un aspecto estético de gran importancia durante el Barroco y la Ilustración, como era la metáfora del triunfo y dominio del hombre sobre la naturaleza. Tal recurso urbano fue desarrollado en Sevilla desde el siglo XVI, con la construcción del gran paseo interior de la Alameda de Hércules, y en su versión exterior más allá de los muros de la ciudad en esa centuria y durante la siguiente, cuando se esbozan las arboledas de Resolana, exteriores de la Puerta de Triana y la Puerta Real, convento del Pópulo y Patín de las Damas; sin embargo, será en el XVIII cuando se defina completamente tal opción por el ornato urbano del entorno de la ciudad.

El Paseo del Arenal, que discurría desde el puente de barcas hasta la Torre del Oro, era ya una de las arboledas ciudadanas más antiguas, como demuestra el hecho de que en el siglo XVI había sido dotada de cuatro hileras de álamos. Su condición se reforzó en el siglo XVIII, cuando se manda por el cabildo en 1725 un nuevo plantío de árboles para extender el número de álamos de esta rivera. El acondicionamiento vegetal corre paralelo a la disposición del paseo y 
a la dotación de asientos, aumentada a comienzos del siglo XIX, siendo obras de gran calado el levantamiento del doble murallón de defensa en la época de la asistencia de López de Llerena entre 1784 y 1785, así como la elevación del puente o alcantarilla de piedra que salvaba la desembocadura del Tagarete y unía este recorrido urbano con el siguiente paseo de Bellaflor. De la importancia de la obra, y del papel destacado que su promotor otorgaba a la misma para la mejora de la ciudad, nos habla el hecho de quedar reflejado entre las mejoras descritas en la leyenda del plano que dedicase a este asistente el geógrafo Tomás López de Vargas y Machuca en 1788, donde se incluiría un levantamiento actualizado del arrabal de Triana, obra realizada por Ginés de San Martín e incluida en el nuevo mapa urbano (figs. $3 a$ y 3b).

Sobre aquel paseo existió una preocupación proyectual ya en la etapa de la asistencia de Olavide, pues conocemos que se hicieron levantamientos para el mismo, a la vez que se trabajaba en el desarrollo de una muralla en el entorno de San Telmo para evitar la erosión del río. Pero la obra más destacada en este tramo ajardinado de Bellaflor, la continuidad del paseo hacia el sur desde más allá de la Torre del Oro, será la efectuada por el arquitecto municipal Félix Caraza entre 1785 y 1787. Caraza dispuso la construcción de una noria y estanque para el riego, en una explanada realizada junto al río Tamarguillo, conformando una platea circular de donde partían dos vías divergentes, una con destino hacia la venta de Eritaña y otra hacia el río. El valor fundamental de la operación fue su perdurabilidad: mantenida la disposición en tridente de sus ramales tras la reforma de Melchor Cano en 1827, la obra de Caraza pondrá las bases de la configuración ajardinada de esta zona sur de la ciudad, carácter que se ha mantenido hasta hoy día. Su diseño aprovechaba la libertad de una forma propia de los jardines dieciochescos en un área no edificada, a través de la técnica del ensanche a través de lo pintoresco, tal como lo califica González Cordón. El valor de esta intervención como nuevo lugar de ocio y su destino hacia la "felicidad pública del pueblo de Sevilla", tal como se manifestaba en la leyenda que en latín y romance que presentaban los frontispicios y lienzos al efecto en el paseo, se unía al recuerdo en sus formas de la arquitectura clásica. El agua de la noria de extracción descendía a una "graciosa fuente con frontispicio" donde unos delfines de piedra arrojaban el líquido para el riego. La fuente y su frontis ocultaban el mecanismo, al modo en que se aconseja tal enmascaramiento en la Architecture bydraulique... de Bellidor. En la rotonda principal se edificaría una fuente con saltos de agua, con seis pirámides y piletas que adornaban sus $\operatorname{caños}^{23}$. En definitiva, se trataba de articular el paseo más pintoresco y alejado del casco histórico de la ciudad como nuevo espacio verde pero ordenado, destinado al ocio ciudadano, y concebido como

23. Arana de Valflora, F. Compendio bistórico descriptivo... pp. 97-98; MatuTe, Anales... Tomo III, pp. 73-74, del que tomamos la transcripción de los lienzos; la intervención en el Paseo de Bellaflor en F. Ollero: Cultura artística..., pp. 321-322 
reencuentro y reflexión sobre lo clásico a través de los lienzos escritos y formas arquitectónicas que remiten a la Antigüedad, que no rehuía sin embargo de un aprovechamiento agrícola con la explotación paralela de ruedos y huertas en este espacio. De este modo, puede rastrearse en la obra de Caraza el influjo de las propuestas de embellecimiento del Madrid de Carlos III, en especial la articulación de nuevas zonas verdes como el Paseo del Prado, y también la repercusión en esta obra de otras operaciones de ajardinamiento, como el proyecto para el Campo Grande de la ciudad de Valladolid, con la disposición en su interior de plateas y vías convergentes ${ }^{24}$.

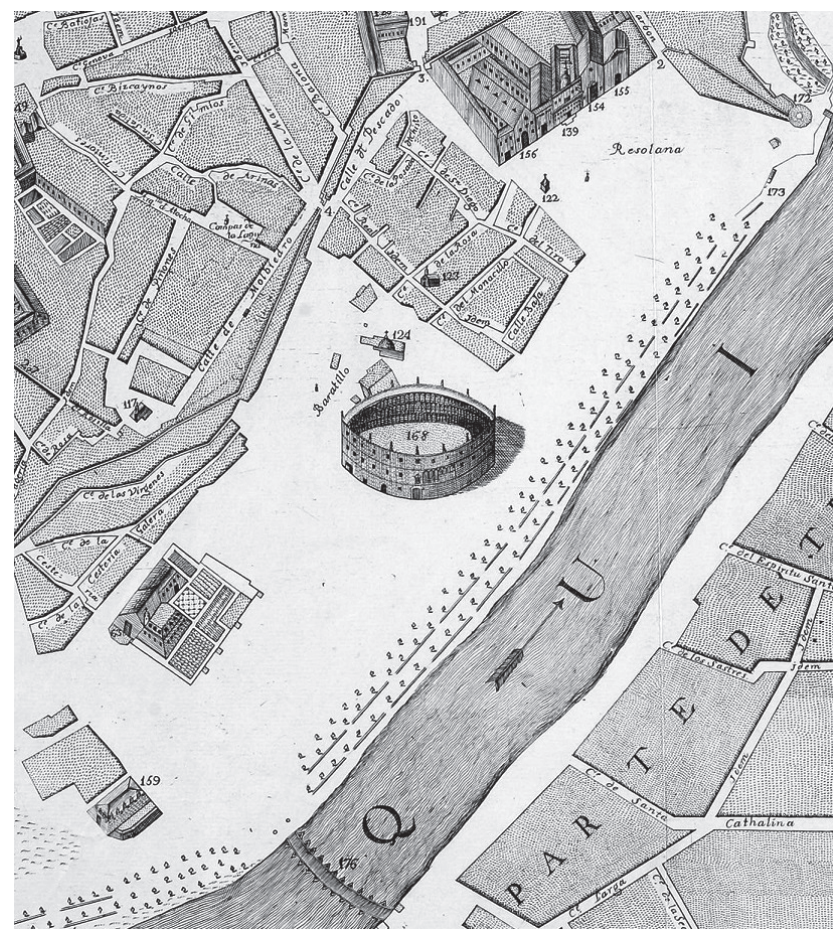

24. Véase entre otros SAmBricio, Carlos. «El urbanismo de la Ilustración: 1750-1814». En Viviendas y urbanismo en España. Madrid: Banco Hipotecario, 1982, pp. 138-157; ReESE, Thomas F. "Hipódromos, carros, fuentes, paseantes y la diversión pública en la España del siglo XVIII: un programa agrario y de la Antigüedad clásica para el Salón del Prado». En El Arte en tiempos de Carlos III. Madrid: Alpuerto, 1989, pp. 1-50. 


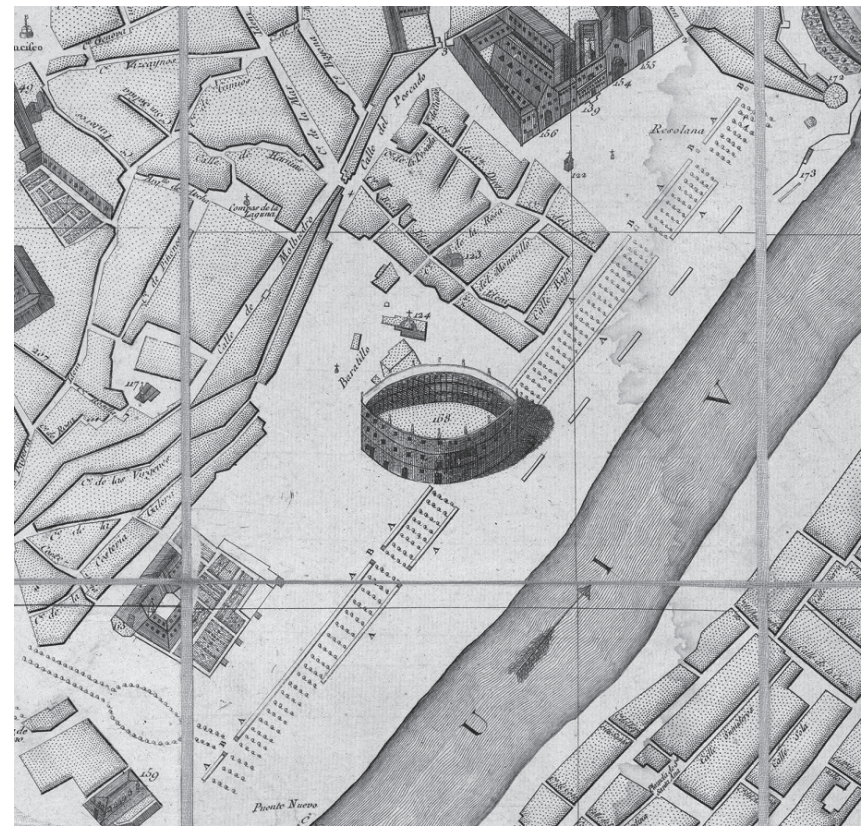

Figuras 3a y 3b. El Paseo del Arenal de Sevilla, en el plano de 1771

y en el Plano geométrico de Sevilla, de Tomás López de Vargas y Machuca de 1788.

Por último, señalaremos en el capítulo de estas intervenciones urbanísticas las que procuraron la apertura de espacios y circulación alrededor del entorno de la Catedral, que se llevaron a cabo desde la década de los cincuenta de la centuria, y que combinaba la eliminación de los restos de lienzos almohades medievales con la supresión del antiguo Corral de Olmos, convertido en ese siglo en un conjunto de dependencias religiosas situadas tras el testero de la Catedral. Ya en 1756 se derribaría los arcos entre el palacio arzobispal y la Puerta de Palos de la catedral. En 1762 se derribaría el arco y torre del Almirantazgo, frente los pies del templo. Hacia el sur, se retranquea la Cruz del Juramento para permitir el libre paso entre el edificio de la seo y la Lonja de Mercaderes, de modo que se visualiza la distancia entre la sede religiosa y la casa comercial, edificio que había definido claramente desde su construcción la noción de inmueble exento del clasicismo, y cuyo valor en el contexto urbano donde se inserta será revitalizado con su conversión en sede del Archivo de la documentación indiana. La finalidad de tales operaciones, que ha estudiado detenidamente Hernández Núñez, era la liberación de añadidos de la seo hispalense y la búsqueda de perspectivas visuales de su fábrica, de acuerdo a criterios estéticos propios del Barroco y desarrollados también en época ilustrada, que aspiraba a potenciar la función representativa de los principales edificios y la percepción monumental de la ciudad y su patrimonio. 
El conjunto de derribos culminó con la decisión del arzobispo en 1790 favorable a la eliminación definitiva de las edificaciones del entorno del antiguo corral de Olmos, en la zona de la actual Plaza de la Virgen de los Reyes ${ }^{25}$.

En realidad, se trata de continuar con el proceso de monumentalización de la urbe a través del desarrollo de perspectivas visuales y aperturas de tránsitos que permitieran la percepción de sus principales edificios, inquietud que se acentuó especialmente en la ciudad con motivo de su capitalidad cortesana durante la estancia de Felipe V. La urbe, que quedase "Viuda" aunque "Reyna de las ciudades" tras la partida de los monarcas, procuró en los años siguientes la consolidación de su imagen urbana. Algunas intervenciones concretas sobre su viario se plasmarían ya en aquellos años en obras de ensanche en el entorno septentrional de la seo, la ampliación de las calles llamadas del Clavel o Peladero, o la pretensión de eliminar un codo de edificios en el ángulo oriental de la plaza de San Francisco para favorecer la visión del edificio de la Real Audiencia ${ }^{26}$.

\section{LaS MURALlas y SU ENTORNO. ARRABALES y EXTRAMUROS.}

Sevilla será aún una urbe rodeada de murallas, muros que adquieren el carácter simbólico de término o conclusión de la ciudad, y que se interpretan en una nueva categoría como patrimonio del pasado y noticia de su grandeza y antigüedad. También existía un claro valor utilitario con defensa -si bien parcial- de las avenidas del río. En esta segunda mitad del siglo, la documentación confirma que no solo se preservan sus lienzos, a través de las peticiones para su uso como parte de edificaciones o mediante denuncias que acusan deterioros en la misma, sino que se restauran conforme las órdenes de los asistentes. López de Llerena, tras la fuerte avenida de 1783, mandó reedificar el perímetro desde la Puerta de San Juan hasta Goles, operación que se glosa en el plano de Sevilla de López de Vargas y Machuca en 1788. El ayuntamiento insistirá en continuar la rehabilitación de muralla tras la riada de 1793, tanto del lienzo situado entre la Barqueta y la Puerta del Sol como del existente entre la Puerta de Jerez y la Torre del Oro, labor apreciada por el arquitecto Félix Caraza en esa fecha en una cantidad cercana al medio millón de reales.

25. Especialmente, véase HERnÁNDEZ NuÑEZ, Juan Carlos. "Transformaciones urbanas en Sevilla durante el siglo XVIII: El derribo del corral de Olmos». Archivo Hispalense, 1993, 232, pp. 89-108; "La construcción de las dependencias catedralicias del ángulo suroeste y su repercusión en el urbanismo sevillano". Archivo Hispalense, 1993, 233, pp. 121-142.

26. La cita en Solis, Antonio de [Lorenzo Bautista de ZuñIGA], autor de Anales eclesiásticos y seglares de la ... ciudad de Sevilla que comprenden la Olimpiada o Lustro de la Corte en ella. Sevilla: Blas y Quesada, 1748 (Colegio de Aparejadores y Arquitecto Técnicos, 1987), pp. 211-212; Ollero, F. "La arquitectura en Sevilla durante el Lustro Real (1729-1733)». En MoralEs, Nicolás y QuiLEs, Fernando (coords.). Sevilla y Corte. La Artes y el Lustro Real (1729-1733). Madrid: Casa de Velázquez, 2010, pp. 85-94. 
Se reparan sus puertas, como la de Triana en 1787, e incluso se levantan nuevas, como la de San Fernando, al término de la nueva calle junto a la Real Fábrica de Tabacos, acceso proyectado por Van der Borcht, y que posiblemente concluiría a fines del siglo José Echamorro. Este arquitecto se encarga igualmente de la reforma de la Puerta de la Macarena, en 1795. Del valor iconológico de las puertas de la ciudad como definición y signo de la propia urbe basta conocer el contenido simbólico que allí desplegara el maestro pintor José Huelva en la pintura que revestía sus muros. En alusión a los orígenes y restauración religiosa de Sevilla se adornaban sus escudos de Santa Justa y Rufina y la entrega de las llaves a San Fernando, y la fundación y grandeza de la Antigüedad con una representación en el intradós del arco donde se ubicaban Hércules y Julio César.

Sin embargo, también en este período continúa la extensión de los arrabales históricos de la ciudad, surgidos cerca de las salidas de la muralla, como es el caso de Triana, que se extiende por la Calle Castilla hacia la salida a Extremadura, el Barrio de San Bernardo o el que se abre en torno a San Roque.

Durante estos años se transforma ampliamente el entorno y las afueras de la Puerta de Jerez. Desde 1758 se construye la calle San Fernando, paralela intramuros a el recorrido de la muralla, tras la cual se abre el alzado principal del edificio de la Real Fábrica de Tabacos, que dota de un extensa construcción civil al entorno tras la Puerta de Jerez y la salida sur de la capital, en correspondencia con el otro gran palacio que venía edificándose desde fines del siglo anterior en ese sector, el Colegio de Mareantes. La escasa interrelación urbana entre estas fábricas, con la conformación de límites de sus propiedades, y la construcción del foso de la Real Fábrica condicionaría el desarrollo de recorridos ortogonales entre sus fábricas y la salida del camino hacia Cádiz, que aseguraban además la perspectiva exterior de estos edificios; uno de estos ramales conduciría tras el ángulo de la fábrica monopolio del estado y por delante del antiguo convento de San Diego hacia el sur, aunque sería el tránsito frente la fachada de San Telmo y enlazando con el camino paralelo al río el que se convertiría en favorito para el paso. La monumentalización de este espacio periurbano lo conformaría como preludio intermedio entre la ciudad y la naturaleza ordenada de su entorno (fig. 4).

La construcción de la citada vía de San Fernando, con sus 21 casas proyectadas para su frente norte, abre un camino de intervención urbana fundamentado en la delineación de vías rectilíneas ex novo, asociadas a la articulación de los espacios ciudadanos en el contexto de la construcción de los nuevos edificios industriales, que sitúan vías en el perímetro de sus alzados como la citada o la existente entre los dos grandes bloques industriales de la Fábrica de Salitre, extramuros en el barrio de San Roque. La innovadora presencia de estas propuestas, frente al mencionado perfil modesto de intervención urbana que la práctica constructiva habitual permitía, constituye ejemplos de excepción en el panorama sevillano. Incluso en estos, el carácter barroco de función perspectiva y la perduración de carácter cerrado de la ciudad se observa en el diseño de la calle San Fernando, la "Nueva» según el plano de Olavide, donde su extremo oriental acaba en una nueva 
puerta para la urbe, levantada en 1760 y cuya composición no se terminaría al menos hasta los años finales del siglo ${ }^{27}$.

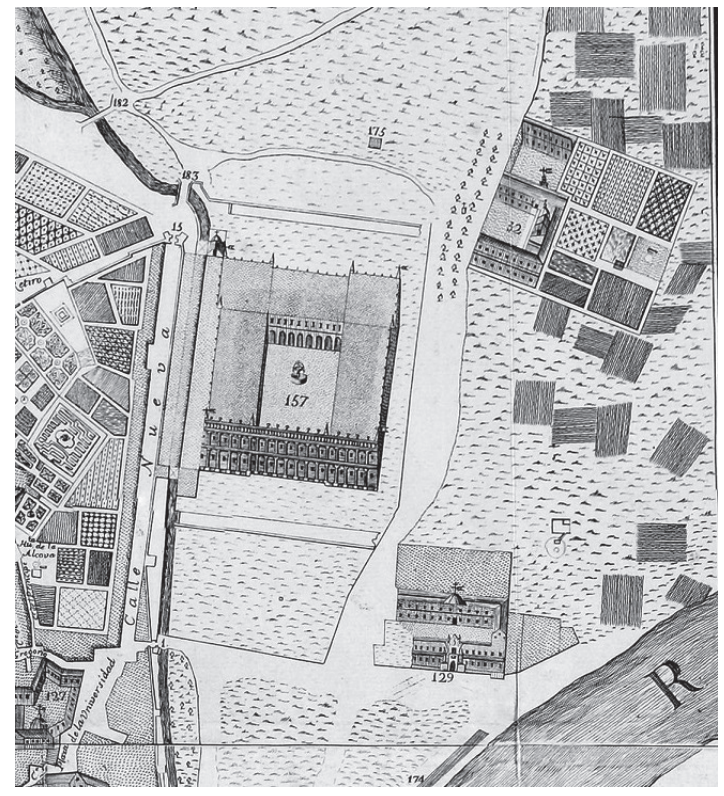

Figura 4. La nueva calle de San Fernando y el sector extramuros de la Puerta de Jerez en el plano de 1771.

También de interés es el caso del crecimiento de los arrabales de la Carretería-Baratillo y Cestería, en las afueras de la Puerta del Arenal, áreas ocupadas al socaire de la expansión comercial de la Sevilla atlántica y americana durante la Edad Moderna, que acabarían uniéndose desde los años setenta del siglo en un único barrio extramuros. Allí se levantan nuevas casas, formando la actual calle Adriano, como el almacén para José Eusebio Cotiella que se levanta con diseño de Ginés de San Martín en 1778 o la edificación de los terrenos fronteros al edificio anterior propiedad de los herederos de Don Pedro Pumarejo y que mide mediante plano gráfico Manuel Mateo en 1785. De este modo, la plaza de toros

27. Suárez Garmendia, José Manuel. "La puerta Nueva o de San Fernando» en Laboratorio de Arte, 1989, 2, pp. 173-182; Morales SÁnchez, José. La Real Fábrica de Tabacos. Arquitectura, territorio y ciudad en la Sevilla del siglo XVIII. Sevilla: FOCUS, 1991 y "La arquitectura doméstica de las Nuevas Poblaciones en la Sevilla del siglo XVIII: La tipología de las viviendas de la calle de San Carlos en Sevilla». En SEnA, G, y Avilés, Manuel (coords.) Nuevas Poblaciones en la España moderna. Madrid: UNED, 1991, pp. 455-468. 
que desde mediados del siglo se está construyendo en material quedará como gran nexo monumental. El asalto demográfico tras la Puerta del Arenal se observa en las disposiciones del cabildo municipal por evitar el desarrollo de mercados de venta extramuros en ese sector de la ciudad, pese a la inquietud de la entidad por ordenar los puntos de abastecimiento en lugares estratégicos dentro de la muralla.

El dibujo concentrado y aún cerrado de la urbe en torno de su cinturón amurallado permitió una cierta ordenación del área exterior hacia el oriente, mediante intervenciones concretas que procuraban la mejora del tránsito desde las puertas de la muralla y de la ronda perimetral. Era un área estratégicamente relevante para Sevilla, señalada por la preocupación por el mantenimiento del abastecimiento de la ciudad, desde el manantial de la Fuente del Arzobispo que daba agua por el norte a buena parte del caserío hasta la Alameda, o la más general de los Caños de Carmona. También era el lugar de salida de importantes accesos, como era el caso del arrecife que conducía a Carmona desde la calle Oriente, pasando por el humilladero de la Cruz del Campo, en dirección a Écija, a través del llamado camino real de Madrid. Planes de mejora del propio municipio, como el iniciado en 1777 para este acceso y los otros principales de Extremadura, Castilleja y Cádiz, permiten verificar el ascendente valor del borde inmediato de la ciudad intramuros, fundamental en su desarrollo posterior. La participación de los ingenieros militares, como en el proyecto de Fernández de Ángulo para el arreglo del camino hacia Écija en 1779, o en los relacionados con la ubicación de cuarteles tras la constitución de la ciudad como mando militar en 1776, con la construcción del de caballería de la Puerta de la Carne bajo diseño de Antonio Hurtado en 1788, potenciarán ese carácter de tránsito paralelo a la muralla de los aledaños exteriores, de donde las vías de salida marcaban transversalmente el posterior dibujo de expansión de la urbe. El dominio de la naturaleza y una limitada ordenación de sus accidentes marcarán el esbozo de un idea de planeamiento de su sector oriental, preocupación que se extiende más allá incluso del cinturón inmediato a la muralla: en 1781 se proyectaría el encauzamiento del arroyo Tagarete, atirantando levemente su cauce, que se salvaba mediante la alcantarilla de los caminos que salían desde la puerta de Carmona y la de la Carne, esta última arreglada en fechas inmediatas a ese diseño ${ }^{28}$.

28. Bernal, Antonio M. "El Guadalquivir durante el siglo XVIII». En La Sevilla de las Luces con las respuestas y estados generales del Catastro de Ensenada. Sevilla: Ayuntamiento, 1992, pp. 59-72; FERnández Chaves, M. F. y Hernández NAvarro, Francisco J. "El arreglo del Arrecife de Sevilla a Ecija, 1779-1780». En Milicia y sociedad ilustrada en España y América: (1750-1800) Actas de las XI Jornadas Nacionales de Historia Militar. Madrid: Deimos, 2003, vol. 2, pp. 413-430; SÁnchez-CorTEganA, José María y PONCE-OrTIZ, Mercedes. «Sevilla: Arquitectura y ciudad militar de 1750 a 1800», Idem, vol. 2, pp. 451-482; Ollero, F. Cultura artística... Op. cit.; Fernández Chaves, Manuel F. Política y administración del abastecimiento de agua en Sevilla durante la Edad Moderna. Sevilla: Diputación, 2012, cap. IV. 


\section{INTERVENCIONES INTRAMUROS}

La urbanización del caserío extramuros de la ciudad, que se desarrolla de modo espontáneo, y que los maestros mayores del municipio tratarán de encauzar en frentes alineados, no implica que el espacio dentro de los muros de Sevilla estuviera completamente urbanizado y habitado. Especialmente desde el terremoto de Lisboa de 1755 son varios los testimonios que revelan el abandono de casas y la presencia de solares vacíos. Se trata legalmente de subvertir este proceso, como pretende la Real Orden del Consejo de Castilla prohibiendo construir en el exterior de la ciudad mientras hubiera espacio disponible ${ }^{29}$. Otros acuerdos municipales, con mayor criterio, pretenden establecer medidas para favorecer el abaratamiento inmobiliario del centro histórico. Aquellos espacios intramuros que no registraban ocupación como consecuencia de factores ajenos a los precios del mercado o la naturaleza de sus propietarios fueron habilitados para su empleo, como es el caso de la Laguna de Santa Lucía, en $1767^{30}$.

La más singular de estas intervenciones fue sin duda la urbanización de un espacio junto a la Puerta del Arenal, en una zona marginal, definida históricamente por el ejercicio de la prostitución, y que incluso había sido objeto de una separación física del resto de la ciudad mediante muros y puertas para limitar su acceso. Se trataba de un espacio conocido como la Laguna, por la existencia de un embalse de aguas permanente en la misma.

El proyecto para la urbanización del barrio se remonta a la asistencia de Julián Robiou, bajo cuyo mandato y en 1760 se ideó la apertura a la calle de la Mar de un nuevo barrio, con el trazado de seis calles con plaza central en su centro. La idea de los miembros del cabildo de situar en su centro una estatua ecuestre del nuevo rey Carlos nos explica claramente la derivación del modelo de place royale junto a un urbanismo en damero para el resto del viario. El plan se demoró hasta la asistencia de Olavide, a través del proceso de enajenaciones para permitir su desarrollo urbanístico. En 1767 se firma el acuerdo para la edificación de casas en el barrio, conforme a la iniciativa de una serie de comerciantes, burgueses representantes de los más florido del comercio y el agro local, en su mayoría oriundos o procedentes del norte de la península, situados políticamente en el centro de las reformas municipales y por tanto, cercanos a la figura del asistente, que apoya el proyecto. Estos prohombres, José Cotiella, Juan Miguel de Ochoa, José Torrecillas y posteriormente Pedro de la Cuesta, encabezados por Manuel Prudencio Molviedro, compran las parcelas y delimitan las propiedades conforme a acuerdo colectivo. La iniciativa fue sancionada en 1769 por una Real Provisión, y para esas fechas y con el asesoramiento del arquitecto Pedro de San Martín, se inician las

29. Aguilar Piñal, F. La Sevilla de Olavide..., p. 39

30. Acuerdo municipal del 28 de septiembre. AMS. Sec. X. Actas Capitulares. Primera Escribanía, 55. 1767 , fol. $141 \mathrm{r}$. 
operaciones para la edificación de la calle principal del nuevo barrio, donde se abren las mansiones principales de los propietarios y patrocinadores del proyecto. A la vez, se ensancha la embocadura del antiguo compás de la Laguna, y se alinea el tramo de la calle Harinas más cercano a su confluencia con la nueva vía, ya en el exterior del sector de manzanas afectadas. El desarrollo urbanístico culminará en 1776 con la configuración de una plaza regular al final de la calle principal y el levantamiento de un edificio para palenque y mercado de sus habitantes ${ }^{31}$ (fig. 5). El plan tendrá indudables paralelos en la extensión de la trama urbana según criterios ortogonales en áreas limitadas de los intramuros urbanos o junto a los mismos, como es el caso del barrio de San Roque promovido en Sigüenza por el prelado Díaz de la Guerra, o del de San Carlos edificado en la ciudad de Cádiz por la Real Junta de Fortificación, y por la participación en su formación o en su destino residencial, de la burguesía y la iniciativa privada ${ }^{32}$.

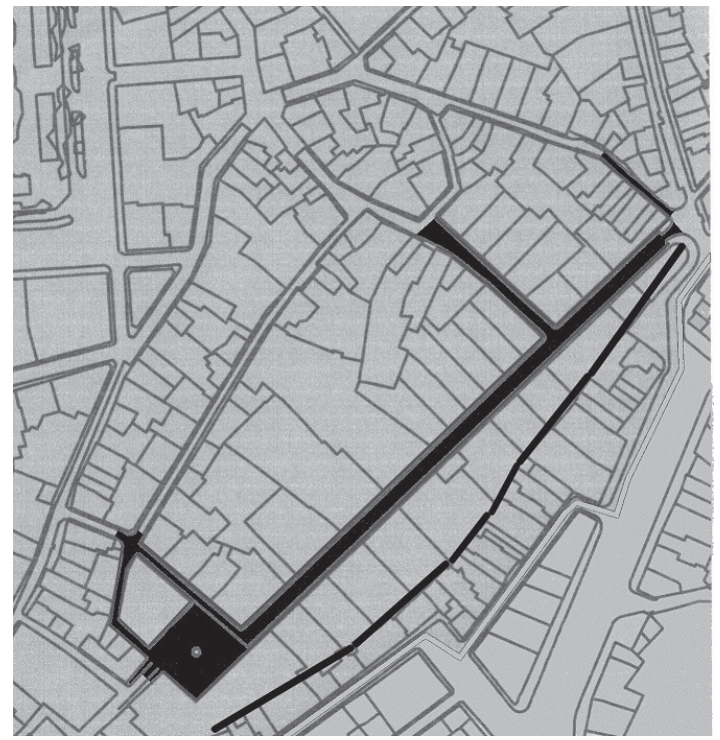

Figura 5. Calles y plaza del nuevo Barrio de la Laguna. 1767-1779.

31. Véase Ollero Lobato, F. El barrio de la Laguna de Sevilla... Op. cit.

32. LARUmBe MarTín, María. "La época ilustrada en la provincia de Guadalajara». Wad-al-Hayara: Revista de estudios de Guadalajara, 1999, 26, pp. 239-289; RUIZ NIETO-GUERRERO, María del Pilar. Urbanismo gaditano en tiempos de Carlos III: formación del Barrio de San Carlos. Cádiz: Universidad, 1994; Historia urbana de Cádiz: génesis y formación de una ciudad moderna. Sevilla: Caja San Fernando, 1999. 
Pese a las acciones descritas, estas intervenciones urbanísticas y el cambio en la manera de concebir la ciudad y sus modos de transformación no supusieron una alteración profunda de su forma urbana, aunque sin duda fue esta una aspiración última del gobierno ilustrado; las Sátiras contra Guindo Cerezo, literatura crítica con el asistente Olavide tras su caída, ponen en su debe moral su voluntad de derribar conventos para hacer nuevas plazas en la ciudad ${ }^{33}$, y con ello se ejemplifica no solo la voluntad reformadora de parte de la política local, sino también los profundos inconvenientes que tales planes tuvieron en el marco tradicional de la capital. Las intervenciones limitadas, incompletas y modestas condujeron a un escepticismo generalizado sobre la transformación de Sevilla. Scipión Perosini, ingeniero de origen italiano comisionado para disminuir el efecto de las riadas, descubría su convencimiento de la necesidad de eliminar la conformación actual de Sevilla y elevarla en altura para solucionar el problema del río ${ }^{34}$; pero ese escepticismo no era solo sevillano; Antonio Ponz se mostraba también radical en la posibilidad de cambiar la ciudad solo mediante la planificación urbana y el efecto del tiempo

Esta mala Planta y deformidad de las Ciudades no se remediará jamás, sino haciéndolas de nuevo; y supuesto que qualquiera de ellas naturalmente se renueva en el término de un siglo, ¿por qué tales renovaciones no habían de hacerse sobre un plan excelente, que estuviese en las casas del Cabildo y Ayuntamientos? ${ }^{35}$.

\section{El SIGLO XIX. LA APERTURA DE PLAZAS Y LA OCUPACIÓN FRANCESA}

Precisamente será una coyuntura histórica traumática, -la invasión y ocupación francesa-, la que se convertirá en una paradoja para el urbanismo sevillano. Junto a la destrucción patrimonial que conllevó la presencia gala en Sevilla, sus consecuencias sobre la trama urbana ofrecerá nuevas posibilidades para esas intervenciones más radicales que aspirase la Ilustración del XVIII.

Durante su estancia en Andalucía en 1810, el rey José Bonaparte insiste en la proyección de una imagen de rey «benefactor», sujeto al anhelo de la felicidad y comodidad pública, unido a la idea de la pacificación en una época de violencia, y auspicio, según la propaganda, de una etapa mucho más feliz tras la derrota definitiva de los enemigos propios y externos. Unido a esta faceta se encuentra

33. Aguilar Piñal, F. «Una sátira sevillana contra Olavide: La «Vida de Don Guindo Cerezo». Archivo Hispalense, 1988, 217, pp. 141-162.

34. Memoria sobre el estado actual del Río guadalquivir, modo de facilitary asegurar su navegación desde el mar hasta Sevilla, y precaverla de los daños que padece de las Ynundaciones. Manuscrito. Citado en Ollero, F. Cultura artística..., pp. 406-409.

35. Ponz, Antonio. Viage de España. Madrid: Imp. Viuda de Ibarra, hijos y Cía. 1786 (Madrid: Atlas, 1972), BAE, IX, carta sexta, p. 96 
su esfuerzo por presentar su figura como rey protector de las Bellas Artes, del que dejará testimonio en la Gazeta de Madrid con diversas normas y decretos relacionados con el campo artístico. En cuanto a las relacionadas con la ciudad hispalense, José I establece en 11 de febrero la ayuda con un pago anual sobre rentas de suelo público para la Real "Academia» de Bellas artes de la ciudad, a solicitud de la institución. Con misma fecha se determina la constitución de el primer museo de carácter oficial de la ciudad, "Queriendo reunir en un mismo sitio todos los monumentos de las bellas artes de esta ciudad", en el interior del Alcázar, de modo que se expusieran al público en él los principales monumentos de arquitectura, medallas y pinturas de la conocida como «escuela sevillana", tal como se indica literalmente en el decreto, génesis de la colección pictórica obtenida por la sustracción de lienzos en distintas entidades de la ciudad, fundamentalmente conventuales, parcialmente llevada después a Francia tras el abandono de los franceses de la ciudad ${ }^{36}$. También Itálica, gran centro del estudio de las antigüedades en Sevilla, visitada por ilustrados como Laborde, sería objeto de atención por parte del monarca, quien manda sufragar las excavaciones del lugar mediante la extracción de una cantidad anual proveniente de las fincas desamortizadas al monasterio de San Isidoro, y obliga al reconocimiento público de la importancia de la antigua población romana mediante la recuperación del nombre de Itálica para el lugar y nueva parroquia constituida tras la supresión del cenobio medieval ${ }^{37}$.

Pero desde el punto de vista urbanístico, los anuncios más relevantes serán los Reales Decretos del 20 y 26 de abril, donde se establecía respectivamente la constitución de una nueva plaza pública en la huerta del convento de San Francisco, y la formación de otro espacio abierto en el solar de la manzana comprendida entre las plazas de Regina y Encarnación, donde estaba situado el convento de agustinas homónimo. Estas decisiones favorables a la constitución de nuevos espacios abiertos se completan en la ciudad con las órdenes para el derribo de la iglesia parroquial de Santa María Magdalena y del también templo de este rango llamado de Santa Cruz, situado en la antigua judería ${ }^{38}$.

36. Alcázar de Sevilla, 11 de febrero de 1810. Publicada en la Gaceta de Madrid, n. ${ }^{\circ} 54$. 23/02/1810, p. 226. El decreto es citado por FERRín PARAMIO, Rocío. El Alcázar de Sevilla en la Guerra de la Independencia. El Museo Napoleónico. Sevilla: Ayuntamiento. Patronato del Real Alcázar, 2009, pp. $79-80$

37. En Itálica, a 8 de febrero de 1810. Publicada en Gaceta de Madrid, n. ${ }^{\circ}$ 51, 20/02/1810, pp. 209-210. http://www.boe.es/buscar/gazeta.php. Citado en CABAllos Rufino, Antonio, FatuarTe, Jesús María y RoDríguez Hidalgo, José Manuel. Itálica arqueológica. Sevilla: Universidad de Sevilla. Fundación El Monte. Consejería de Cultura de la Junta de Andalucía, 1999, p. 44.

38. Formación de estas plazas sevillanas en Mercader, Joan. José Bonaparte, Rey de España. Madrid: CSIC, 1971, vol. 2, p. 449; SuÁrez GARMENDIA, José Manuel. Arquitectura y urbanismo en la Sevilla del siglo XIX. Sevilla: Diputación, 1986, pp. 23-24 y ss; la apertura de plaza pública en la Huerta del Convento de San Francisco en Sevilla, a 20 de abril de 1810, fue publicada en Gaceta de Madrid núm. 127, de 07/05/1810, p. 532; la de la supresión del convento de la Encarnación en suplemento de 
Las ideas reformistas del rey José sin duda aparecen como motivación inicial de estas modificaciones de la ciudad tradicional; conocedor de las intervenciones urbanísticas más señaladas del París napoleónico, durante su etapa como máxima autoridad de Nápoles verá los inicios de la formación de la plaza Napoleone, actual del Plesbicito, en la capital italiana; sabemos de su interés personal por estos aspectos, que se demuestran en las anotaciones realizadas a los proyectos de Silvestre Pérez para su monumental intervención en la ciudad de Madrid.

Sobre estas estos últimos diseños gravita el prurito de imitación de la Antigüedad clásica, en este caso asimilado a la idea de poder imperial, que hace dotar a las formas urbanísticas de los espacios napoleónicos de esas referencias tan rotundas a los foros romanos, con el uso de espacios cerrados, exedras y perspectivas focales. De este modo, la propaganda de la grandeza a través de los hechos militares y la acción benéfica del estado se convierten en trasunto o inspiración de tales actuaciones. El caso concreto que nos ocupa, mucho más modesto, de la apertura de plazas, reiterado en diversas ciudades de las ocupadas en España por los franceses, parece manifestar la necesidad estratégica de contar con espacios abiertos en los núcleos urbanos para concentrar las tropas que evitasen la revuelta interior o la invasión exterior, además de concordar con los ideales propios del urbanismo ilustrado, con la búsqueda de una ciudad más ordenada y racional.

Algunos precedentes o acciones coetáneas de este urbanismo español durante la ocupación francesa tuvieron el objetivo de abrir nuevos ejes de comunicación en el interior de las ciudades, como es el caso del proyecto de Valladolid del general Kellermann para conectar la plaza mayor y la de la Comedia ${ }^{39}$, o especialmente el monumental de Silvestre Pérez en la capital del Reino para unir en un eje institucional el Palacio Real y San Francisco el Grande, transformada en sede de las cortes. Tales ejemplos hicieron exponer a Suárez Garmendia la hipótesis, luego retomada por Carlos Sambricio, de un plan preconcebido para conectar mediante un nuevo eje norte-sur la trama intramuros de la ciudad de Sevilla, desde la Puerta de la Barqueta hasta la del Arenal ${ }^{40}$.

Pero la apertura de estos nuevos espacios constituía en sí mismo una motivación posiblemente relacionada con esa faceta pedagógica tan personal del monarca José I, que pretende hacer visible los efectos positivos para la ciudad de la eliminación de las grandes superficies conventuales, que condicionan negativamente la circulación por el interior de las ciudades y la reforma de su trama. Sin duda este aspecto, tal como hemos comentado, no estaba alejado de los anhelos

la Gazeta extraordinaria de Sevilla, de 28/1V/1810, según transcribe Joaquín Guichot en Historia del Excmo. Ayuntamiento de Sevilla.

39. Redondo CANTERA, María José. "La política bonapartista sobre los bienes artísticos desamortizados del clero regular y su repercusión en un medio provincial: Valladolid, 1808-1813". Academia, 1991, 73, pp. 253-259.

40. Territorio y Ciudad en la España de la Ilustración. Madrid: Ministerio de Obras Públicas y Transportes, 1991, vol. 2, pp. 598-600. 
de algunos miembros de la administración ilustrada y el cabildo en la propia ciudad, tal como se interpretaba por sus contemporáneos la posición de Olavide, o en la idea de configurar la ciudad como un sistema. En este sentido cabe señalar la figura de Joaquín Goyeneta, hacendado fundador del Consulado Nuevo en la ciudad, procurador mayor y veinticuatro de su cabildo, que sería nombrado en dos ocasiones presidente del cabildo municipal, una como corregidor durante la ocupación francesa (1810-1812) y otra al regreso de Fernando VII a España (18141816). De talante liberal, Goyeneta se situó en favor de la legalidad en el cumplimiento de las órdenes relativas a la constitución de los cementerios rurales frente a la reacción eclesiástica y sus seguidores en el cabildo; igualmente, hemos visto su posición favorable a un "sistema constante» que diera "seguridad, hermosura y comodidad" a la ciudad de Sevilla ${ }^{41}$. Plan integral y acciones concretas que la invasión francesa convertía, de manera traumática, en una oportunidad cercana.

Todo este prurito urbanístico del poder político y militar del invasor se corresponde, además, con una mirada previa propiamente española e ilustrada. En los primeros años de esta centuria se desarrollan en Sevilla una serie de propuestas, anteriores o coetáneas a las que fueron resultado de la ocupación francesa, que manifiestan la continuidad de las ideas ilustradas y los primeros planteamientos para la resolución mediante plazas de nuevos espacios públicos. De 1805 es el proyecto de plaza-mercado, diseñado por el maestro mayor de la ciudad Félix Caraza para el Altozano de Triana, en el solar dejado por la demolición del antiguo castillo de San Jorge. Se trataba de configurar un espacio cerrado, porticado y de forma cuadrangular, con destino a mercado del arrabal, y con fachada principal hacia el río ${ }^{42}$. La plaza se organizaba mediante calles con soportales que partían de su centro hacia el Altozano y Castilla, y otras secundarias que abrían hacia San Jorge y el Guadalquivir, mientras que el acceso al curso fluvial se hacía a través de una escalinata, una comunicación de carácter monumental que recuerda soluciones análogas y anteriores como la empleada en el Patín de las Damas.

Esta intervención se convierte en el precedente inmediato en el contexto local para la plaza que se quiere construir en la huerta del convento Casa Madre de los franciscanos en Sevilla. Conocemos su aspecto en el momento inmediatamente posterior a su creación por un plano elaborado por Cayetano Vélez en 1810. Su autor, un arquitecto jerezano de formación tradicional, había desempeñado labores de segundo alarife maestro de obras de aquella ciudad, pero renovó su oficio

41. Véase nota 8. Posición sobre los cementerios en José VelázQuez y sánchez, José. Anales de Sevilla de 1800 a 1850. Sevilla: Imp. De los Hijos de Fe, 1872 (Ayuntamiento, 1994), pp. 39 y ss. Su posición en la ocupación francesa en Moreno ALOnso, Manuel. Sevilla napoleónica. Sevilla: Alfar, 1995, pp. 175 y ss., y CAMPESE GAllego, Fernando Javier. Los comuneros sevillanso del siglo XVIII. Estudio social, Prosopográfico y Genealógico. Sevilla: Fabiola de Publicaciones Hispalenses, 2004. pp. 127 y 297, entre otras.

42. Publicado por Flores Moscoso, Ángeles: "Noticias históricas del Castillo de Triana». Archivo Hispalense, 1993, 232, pp. 33-54. 
con el contacto con el núcleo academicista gaditano y la amistad con Isidoro Bosarte. En Sevilla, actuó como maestro mayor de la ciudad desde 1809, y participó como tal en proyectos y obras ciudadanas tanto para la Junta como durante la ocupación de los franceses ${ }^{43}$.

La superficie representada consistía en un amplio espacio rectangular interior, cerrado al perímetro de las calles exteriores, que se situaba sobre una zona demolida del antiguo convento, en concreto el área correspondiente a la parte central de la antigua huerta del cenobio, entre las edificaciones del convento y las del también franciscano de San Buenaventura. A esta nueva plaza solo se accede, según el plano, a través de una abierta ex profeso desde la calle Catalanes.

La irregularidad de sus frentes confirma el hecho de que se trata de un espacio definido en el vacío de la demolición, pero no en cuanto a la alineación de esos alzados. Se configura como una forma cerrada, que la documentación relaciona de manera difusa con un uso residencial, por cuanto una parte de la confluencia de la calle dibujada con la futura plaza había sido comenzada a labrar con el objeto de situar en ella unos baños, promovidos por el francés Meyer, asentista del ejército ocupante, un personaje dedicado durante su estancia sevillana a los negocios asociados a la construcción y a las artes, como sugiere su participación en la organización de las celebraciones galas para el mariscal Soult. En definitiva, y por lo que podemos deducir de la única vía de acceso construida y su aspecto general, aún no completamente definido en cuanto a planta y alzado, se observa el influjo de la tradición hispánica de plazas mayores, si bien la preocupación del diseño por la regularidad de sus vías de acceso al respecto de los frentes revela también la inspiración en los modelos de plazas reales francesas ${ }^{44}$.

La imprecisión en cuanto a formas y usos de la plaza del Convento de San Francisco indica más bien la ausencia de un planteamiento previo para esta obra urbana en el contexto de la ocupación francesa, y con ello nos aleja de la idea de una operación predeterminada para definir un eje de paso a través de la Sevilla intramuros. Posteriormente el cabildo con Goyeneta al frente se opondrá a la actividad inmobiliaria de Mayer, que condicionaba el diseño final del espacio, y promovía el debate sobre el uso final del mismo. En enero de 1812 el procurador del municipio Francisco Cavaleri se muestra partidario de dar un uso cívico a la nueva superficie, en el sentido ilustrado y reformista que se pretende potenciar

43. Sobre Vélez, SuÁrez Garmendia, José Manuel. Arquitectura y urbanismo en la Sevilla del siglo XIX. Sevilla: Diputación, 1986; MoRALEs, Alfredo J. «Las honras fúnebres por Floridablanca en Sevilla y el túmulo proyectado por Cayetano Vélez» en Academia, 73 1991, pp. 179-190; MADRID Álvarez, Vidal de la. "Notas sobre los diseños de autores españoles conservados en la academia de San Lucas de Roma». En Actas del VIII Congreso Español de Historia del Arte. Mérida: Universidad de Extremadura, 1992. vol. 1, pp. 497-502; Ollero, F. “Ceán, Itálica y las Artes en Sevilla». Op. cit.

44. Salinas Alonso, Víctor. "Dos planos del convento y huerta de San Francisco en Sevilla". Atrio, 1991, 3, pp. 171-174; Ollero Lobato, F. «Propuestas urbanísticas para el área del convento de San Francisco de Sevilla durante la primera mitad del siglo XIX". Archivo Hispalense, 2002, 258, pp. 135-152. 
para la mejora de la ciudad; de ese modo planteaba que si el edificio conventual se mantenía para la posteridad, se destinase para biblioteca pública el solar obtenido, pero, en el caso de que desapareciera finalmente el convento franciscano, se llamase a un arquitecto capacitado para construir plaza pública, incorporando los terrenos del recién incendiado convento de San Francisco, de modo que "para que qualesquiera edificio que su circuito haya de construirse guarde la regla de uniformidad en todas sus dimensiones y perspectiva que corresponde a la valentía y elegancia del todo" ${ }^{45}$.

\section{El REINADO DE FERNANDO VII}

Con la llegada de la monarquía de Fernando VII, se observa de manera genérica la continuidad de las ideas ilustradas y en especial de la utilidad pública para las reformas urbanas. Este espíritu es especialmente relevante en los consistorios de los períodos liberales, y dentro de los mismos, en el caso de los representantes municipales del común, entre los síndicos, tal como hemos visto en el caso de Cavaleri.

Junto al sentido de utilidad, y sus derivaciones artísticas hacia el concepto de unidad de composición y predominio de la perspectiva, destaca ahora la definitiva conciencia de la dificultad para el desarrollo de las intervenciones urbanísticas en el marco de la ciudad coetánea, entendiéndose esa dificultad como la diferencia entre el plan ideal y las posibilidades reales de una verdadera transformación urbana. Tal concepto aparece claramente reflejado en las operaciones realizadas por José Echamorro en 1821 para la reforma de la Plaza del Pan. Echamorro se manifiesta partidario incluso de la eliminación de esta plaza, por cuanto este espacio abierto suponía no más que un ensanchamiento de las calles en el testero de la iglesia del Salvador, en una forma de ángulo agudo contraria a la regularidad. De todos modos, desarrolla únicamente el encargo de alinear y diseñar la composición de los alzados del frente este de la plaza, aún en la consciencia de la modestia de esta operación frente al ideal planteado ${ }^{46}$.

Esta cuestión de las dificultades impuestas desde la ciudad tradicional no se limitaba a la continuidad pasiva del objeto físico, sino también a una cierta resistencia por parte de sectores de sus habitantes a los cambios sugeridos. En este punto puede vislumbrarse diferencias de criterio entre la facción política liberal, más decididamente abierta a las reformas urbanas, frente a grupos favorables al poder absoluto del rey. Parecen ubicarse junto a esta última facción los antiguos propietarios de fincas afectadas por las medidas, que sostienen su argumentación

45. AMS. Sec. VII. Escribanía de Cabildo del siglo XIX. Invasión Francesa. Tomo 4. Exp. 30. Rollo 269. Informe del síndico fechado el 28 de enero de 1812.

46. Ollero, F. «La Sevilla soñada. Plazas y ciudad en los inicios del siglo XIX». Atrio, 2006, 12, pp. 81-94. 
en la crítica de la actuación municipal de los grupos más innovadores, y también buena parte de la iglesia local, que solicita el pago de compensaciones por los bienes eliminados o alterados tras la invasión francesa. Fundamentalmente, el cabildo eclesiástico promoverá la reocupación del espacio sacro afectado por las actuaciones urbanísticas, tal como se observa en la propuesta de reconstrucción de las parroquias de Santa Cruz y de la Magdalena, templos de los que se inició su derribo tras el decreto napoleónico de apertura de nuevos espacios públicos. La extinción de la ocupación francesa había dejado incompleta la demolición de ambas iglesias; así, en 1813 los vecinos de la parroquia de Santa Cruz solicitaron la definitiva eliminación de sus restos.

En 1816 el cabildo eclesiástico remitió planos a Madrid para las nuevas parroquias de Santa Cruz y de Santa María Magdalena, diseños realizados por Fernando Rosales, maestro mayor de obras del arzobispado, y que fueron enviados con la finalidad de obtener la aprobación preceptiva de la Real Academia. El día 9 de junio de ese año la junta ordinaria evaluó los planos remitidos por Rosales, que no se aprobaron en razón de la escasa entidad de su autor y de carecer de las debidas "proporciones, orden y decoración que corresponden a las buenas reglas del arte..." ${ }^{47}$. En consecuencia, se remitió informe al cabildo y se remitieron dos nuevos proyectos elaborados desde la academia para ambas iglesias, en limpio y con las modificaciones debidas, que fueron aprobados por la junta ordinaria el 11 de mayo de 1817. Al menos uno de ellos, el de una nueva parroquia de Santa Cruz, fue enviado por el arquitecto Tiburcio Pérez y Cuervo a la real institución, con cinco planos en limpio y según las indicaciones del Director de arquitectura Juan Antonio Cuervo ${ }^{48}$. Como resultado de estas propuestas y de la intención del cabildo, el espacio resultante de los derribos de las parroquias entraría en una fase de indefinición, aún no resuelta para el caso de la futura plaza de Santa Cruz en 1830, cuando quedaban aún restos pendientes de su eliminación; la plaza de la Magdalena sí vería el inicio de la construcción del nuevo templo, que quedaría pendiente hasta el definitivo abandono de su edificación y la ordenación de la nueva plaza en 1844 .

47. 18 de mayo de 1816. Archivo de la Real Academia de San Fernando de Madrid. 33-3/2. Exp. 34. ARASF, según expediente fechado a 21 de abril de 1817. 7-3his/2. Cfr. Ollero, F. Cultura artística e Ilustración... p. 294 y notas 35 y 36.

48. Remitidos a la academia con fecha 22 de febrero de 1817. ARABASF. 33-3/2. Dos de esos planos están depositados en los fondos del Archivo de la Catedral de Sevilla. Vid. Heredia, María del Carmen y Romero, Purificación. "La antigua y la actual parroquia de Santa Cruz". Archivo Hispalense, 1974, 175, pp. 139-164; SuÁrez Garmendia, J. M. Arquitectura y Urbanismo...; Luna Fernández-Aramburu, Rocío y Serrano Barberán, Concepción. Planos y Dibujos del Archivo de la Catedral de Sevilla (siglos XVI-XX). Sevilla: Diputación, 1986; COllantes DE TerÁN SÁNChEZ, Antonio; CruZ Villalón, Josefina, Reyes Cano, Rogelio, Rodríguez Becerra, Salvador (dirs.). Diccionario Histórico de las calles de Sevilla. Sevilla: Consejería de Obras Públicas. Junta de Andalucía. Ayuntamiento, 1993, tomo 2, 56-57 y 346-347. 
La intervención urbanística más importante de la primera mitad de siglo, en donde se plasma igualmente el conflicto entre los ideales señalados y la conformación tradicional de la ciudad, será la reforma de la plaza de la Encarnación, en pleno centro de la Sevilla histórica.

La solución a la función de este espacio abierto tras los decretos napoleónicos vendrá determinada por la decisión del cabildo municipal, plasmada desde 1813, de levantar en su interior un mercado, asumiendo el papel tradicional de la plaza como lugar propicio para el abastecimiento de la población. El mentor del proyecto fue Guillermo Jaramillo, teniente de caballería, y su idea sería desarrollada en 1814 por Cayetano Vélez. Tras unos años de interrupción, en 1818 sería enviado a Madrid el diseño del mercado, formado por cuatro crujías con dobles naves, dispuestas en sentido longitudinal, y fuente central, junto con un proyecto del mencionado arquitecto con el diseño de los alzados de los frentes de la plaza. Ante la negativa académica a su aprobación y la inacción del Consejo de Castilla, el ayuntamiento decidiría en 1820 retomar por sí las obras, levantando un mercado de madera, elaborado por el maestro de obras José Echamorro. La construcción del mercado supuso la ocupación de un recinto interior en la plaza, previo incluso a la alienación de sus frentes, de forma rectangular, dividido en cuatro áreas por calles dispuestas en sus ejes menor y mayor, cada una de las cuales a su vez se subdividían en espacios ocupados por cajones en el perímetro y palenques en su interior. Este mercado perduraría hasta la construcción de uno de material, iniciado por Melchor Cano en 1832 (fig. 6).

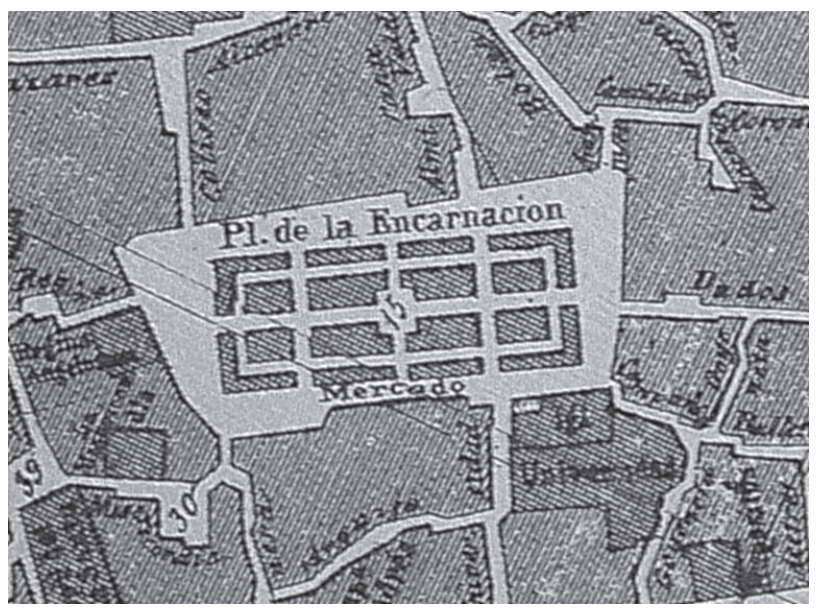

Figura 6. La Plaza de la Encarnación en el plano de Sevilla de Álvarez-Benavides y López, 1868. 
En realidad, este papel de la plaza como mercado establece una especial continuidad con una función del espacio público que se perpetuaba desde la Edad Media. Durante la Ilustración, la reforma de estos espacios en Sevilla había caminado en un doble sentido. Uno de ellos era práctico, que evaluaba en una escala mayor la necesidad de abastecimiento para sectores y barrios distintos de la ciudad, por lo que el municipio aconsejaba u ordenaba la ubicación de palenques dispersos geográficamente para atender tal necesidad, como vimos en el caso de la obligación impuesta a Molviedro para que la plaza del nuevo barrio de la Laguna se destinase a esos menesteres. La otra cuestión era un problema más arquitectónico, que se resumía en la duda entre la opción por adaptar para el uso mercantil las plazas existentes, mediante esquemas ordenados de puestos y calles dedicados a tal función, o el diseño específico de espacios públicos para tal fin. Entre la primera de estas opciones cabría contar los intentos de dotar de puestos ordenados a la plaza de Salvador, fechados en 1793, que pretendía extenderse hasta la plaza del Altozano y Feria ${ }^{49}$ y entre los segundos, el mencionado diseño de plaza-mercado de Caraza para San Jorge de Triana. La intervención prevista sobre la Encarnación avanzaba más bien en la idea de la adaptabilidad de la plaza, decisión verdaderamente obsoleta para la Academia y su afán por organizar el diseño arquitectónico en tipología y función. Autores ilustrados como Valzania, advierten sobre la necesaria separación de la venta de comestibles y la plaza pública $^{50}$. Con una opción más sincera de ocupación del espacio aprovechable, cabe señalar el rumbo tomado por el solar del antiguo castillo de la Inquisición, que será definitivamente acondicionado como plaza de abastos, para el que levantará planos el propio Echamorro en 1821 y será finalmente proyectado por Tomás Escacena al año siguiente.

Sin embargo, nos interesa destacar ahora que la ordenación de este recinto no estuvo vinculada desde su origen hacia esa función. Los propietarios de las fincas afectadas en la plaza elevaron al cabildo una memoria donde declaraban que la intención de intervenir abriendo nuevo espacio público se remontaba a un período anterior al de la invasión napoleónica ${ }^{51}$; en este sentido, hay que recordar que la supuesta intención de Guindo Cerezo-Olavide de «unir dos espaciosas plazas, mediando un convento de monjas», se aproxima mucho a la solución emprendida

49. Fernández GonzÁlez, Alberto. "Arquitectura y mercado en la Sevilla del siglo XIX: La plaza de abastos de Triana". Archivo Hispalense, 2010, 282-284, pp. 465-486 y "Ciudad y mercado en Sevilla: El trienio liberal (1820-1823)». En SERrano, Felipe (Coord). Docta Minerva. Homenaje a la profesora Luz de Ulierte Vázquez. Jaén: Universidad de Jaén, 2010, pp. 249-260.

50. "Entre las varias Plazas, que para su desahogo necesita tener una población de consideración, la principal debe estar en el centro de ella.... más su destino no debe ser la venta de comestibles, pues para este efecto es más conveniente hacer en sus inmediaciones varias Plazuelas, en donde se puedan colocar con distinción y arreglo» (VALZANIA, Francisco Antonio. Instituciones de arquitectura. Madrid: Imp. de Sancha, 1792. Cap. III, artículo VI, p. 68).

51. Suárez Garmendia, J. M. Arquitectura y urbanismo..., op. cit. pp. 61 y ss. 
posteriormente en la Encarnación. Desde 1810 al menos, existe constancia de la existencia de un proyecto de Cayetano Vélez para configurar los frentes de la nueva plaza con una alineación rectilínea, en el que estaría previsto un nuevo atirantado de sus frentes. De este modo, y de manera previa a la decisión de convertirla en una plaza-mercado, aparece para los más innovadores en el gobierno de la ciudad como una oportunidad por dotar a Sevilla de una plaza mayor, al estilo de las plazas neoclásicas que a la sazón se estaban construyendo en el norte de España. De una manera expresa, se cita el modelo de la de la villa y corte, de modo que el resultado constituyera para la urbe «una plaza digna de tan grande capital y acaso la mejor del Reyno" ${ }^{52}$. La prevención hacia el futuro urbanístico de la ciudad, de acuerdo con la idea esbozada de las dificultades actuales y la mejora de la ciudad futura era manifestada con claridad, pues se consideraba "necesario que el Ayuntamiento estienda también sus miras a lo venidero y remueva estorbos a la posteridad"

La plaza debía constituirse de acuerdo a la alineación de sus frentes y la homogeneidad de sus alzados. Ya el proyecto de plaza de Vélez incluía un proyecto para su composición, de carácter monumental y cercano a los ejemplos del barroco romano. Se trataba de un alzado de un edificio homogéneo y simétrico, de dos cuerpos, el primero de ellos entendido como un alto basamento, con un segundo articulado mediante la sucesión de vanos rectangulares, animados solo por una guirnalda en sus antepechos. Sus accesos se disponían en los extremos y en el centro del alzado, mediante arcos de entrada y balconada. El plan sería rechazado por la academia, que aduciría falta "de comodidad, hermosura y decoración» 53 . Pero cuando el ayuntamiento retoma en 1820 con el Trienio Liberal la ordenación de la plaza, más allá de la opinión de la corte, decidirá, a la vez que la construcción del mercado en madera, un concurso para la elección de un modelo común de sus fachadas. Los miembros del cabildo municipal optaron como condiciones el que se compusieran los frentes de estas casas con una altura de veinte varas, con tres pisos de altura y un recorrido interno mediante soportales (fig. 7). Finalmente será el maestro mayor de obras José Echamorro el que se postule como autor de esos alzados. El asunto quedó en suspenso durante años, interrupción a

52. AMS. Sec. IX. Tomo 27. Exp. 9. Opinión de los síndicos solicitada por acuerdo municipal del 13 de diciembre de 1820. Informe fechado en 30 de abril de 1821. Fols. 2r-5v. La cita (4v) en Aguilar PIÑal, F. "Algo más sobre la Encarnación». En Temas Sevillanos. Sevilla: Universidad de Sevilla, 1988, pp. 243-254.

53. FERnÁNdez GonzÁlez, Alberto. "Arquitectura y urbanismo en la Sevilla ochocentista. La plaza-mercado de la Encarnación”. Anuario del Departamento de Historia y Teoría del Arte, 2009, 21, pp. 205-22 y "Memoria histórica de un fragmento urbano de Sevilla: El espacio de la Encarnación entre los siglos XVI y XXI». En BarRal Rivadulla, María Dolores; Fernández CaStiñeIRAs, Enrique; FernándeZ Rodríguez, Begoña, y Monterroso Montero, Juan Manuel (coords.). Mirando a Clío: el arte español espejo de su historia: actas del XVIII Congreso del CEHA, Santiago de Compostela. Santiago de Compostela: Universidad de Santiago de Compostela, 2012 [CD]. 
la que no seran ajenas, entre otras causas, las turbulencias políticas del período. En 1824 el asistente, el cabildo y el arquitecto Silvestre Pérez acordaron, según Ceán, un proyecto para la plaza de la Encarnación, con medidas de su superficie, frentes y propuestas de alzados, que contaron con el beneplácito de la Real de San Fernando, y que no se llevaría a efecto ${ }^{54}$. Finalmente, sería el arquitecto Melchor Cano quien realizaría desde 1832 la alineación y fachadas, con diseño aprobado por la Academia. Los alzados de Cano se construyeron según ese dibujo de acuerdo con una arquitectura doméstica más evolucionada y sintética, donde desaparecieron los soportales, y se disponían en altura tres pisos separados por cornisas y remate en pretiles; aún la tardía intervención de Cano no completaría el recorrido completo de los frentes de la plaza. Más tarde, el proyecto se olvidaría, puesto que la preocupación por dotar a la ciudad de un espacio semejante se trasladaría en el plazo de unos años a la plaza Nueva, abierta en los terrenos del desaparecido convento de San Francisco.

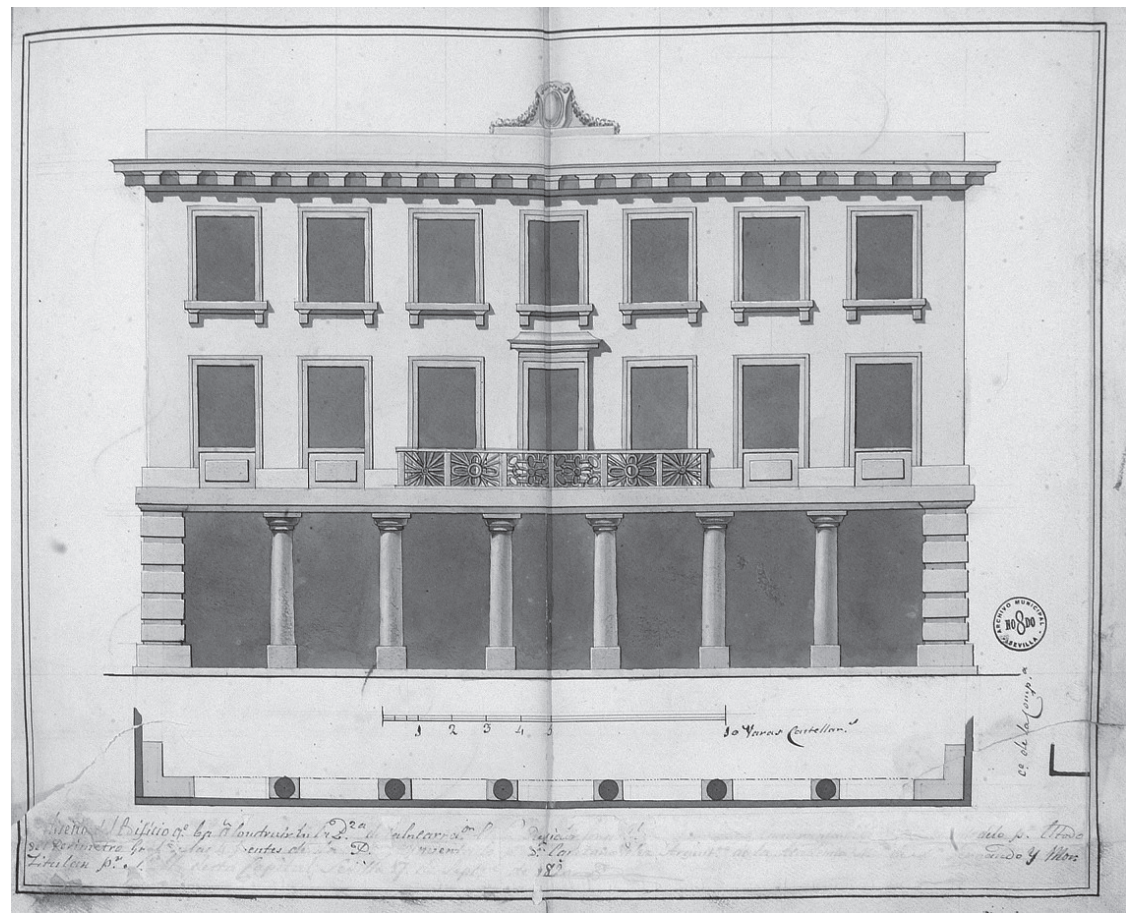

Figura 7. Diseño de edificio para la plaza de la Encarnación...

Arquitecto Cayetano Vélez, 1820 (Archivo Histórico Municipal de Sevilla).

54. Sambricio, Carlos. "Noticia sobre Silvestre Pérez...», op. cit. 
La idea de levantar una auténtica plaza mayor en el mismo centro de su trama urbana no solo tendría como resultado esta preocupación por su diseño interior, sino que afectaba directamente, y de acuerdo a esta previsión de un plan para la modificación venidera de la ciudad, a las calles adyacentes, que se comprendían relacionadas estructural y formalmente con el nuevo espacio urbano. Con este sentido desarrolló Echamorro en 1821 el proyecto de alienación de calles desde la Plaza de la Encarnación hasta Francos, por sugerencia directa de los síndicos municipales. El proyecto, que postulaba la alineación en frentes rectilíneos de la calle Lineros y su continuación en Francos hasta su bifurcación en Conteros, en la cercanía de la catedral, se debía entender también como resultado de las opiniones de este arquitecto en relación con la eliminación de la Plaza del Pan.

De este modo, se pretendía configurar, ahora sí, un nuevo eje civil y laico, determinado por la centralidad de la Encarnación hasta el área monumental y religiosa, conforme a la regularidad formal y la visión en perspectiva de la nueva plaza. Se trataba para los síndicos y el arquitecto del inicio de un plan de reformas que considerase esa finalidad para la transformación posterior del viario ciudadano, de modo que «... que el Excelentísimo Ayuntamiento trabaje y estienda sus miras venéficas, no solo para la generación presente sino para las venideras, y que no les deje estorbos para las mejoras que quieran hacer en la planta de toda la ciudad ${ }^{55}$.

La importancia principal de este diseño no realizado de Echamorro es constituirse en el primero de los proyectos decimonónicos de alineaciones, anterior incluso al que desarrollaría Melchor Cano para la Alfalfa y calle Mesones de 1831. Significaba un nuevo tipo de intervención urbanística a mayor escala, según un concepto de intervención sobre un plan preestablecido, de las que se habían proyectado en la Sevilla ilustrada, aunque respondiendo también a las recurrentes expectativas de contar con un plan general para la ciudad, una noción esta, la del proyecto de Echamorro, que solo será desarrollada muy posteriormente en Sevilla, y con desigual éxito, en los planes de ensanches que se elaborará para la ciudad en fechas muy posteriores.

\section{BIBLIOGRAFÍA}

Aguilar PiÑal, Francisco. La Sevilla de Olavide (1767-1778). Sevilla: 1965 (Ayuntamiento, 1995).

Aguilar Piñal, Francisco. "Un paseo por la Sevilla de Olavide». En Historia del Urbanismo Sevillano. Sevilla: Real Academia de Bellas Artes de Santa Isabel de Hungría, 1972, pp. 107-131.

Aguilar PIÑal, Francisco. Historia de Sevilla. Siglo XVIII. Sevilla: Universidad de Sevilla, varias ediciones.

55. AMS. Exp. 32. Informe de los síndicos del 21 de febrero de 1821. (1v.). Francisco OlLERO LoBATO. "La Sevilla soñada. Plazas y ciudad...", op. cit. 
Aguilar Piñal, Francisco. «Una sátira sevillana contra Olavide: la Vida de Don Guindo Cerezom. Archivo hispalense, 1988, 127, pp. 61-70.

Albardonero Freire, Antonio José. El urbanismo de Sevilla durante el reinado de Felipe II. Sevilla: Guadalquivir, 2002.

Angutta Cantero, Ricardo. "La concepción teórica de la idea de ciudad en la Ilustración española: la Policía urbana y los nuevos fundamentos de orden, comodidad y aspecto público». Cuadernos de arte de la Universidad de Granada, 1996, 27, pp. 105-120.

Angutta CANTERo, Ricardo. Ordenanza y policía urbana: los orígenes de la reglamentación edificatoria en España (1750-1900). Granada: Universidad, 1997.

Arana de Valflora, Fermín (seud. de Fray Fernando Díaz Valderrama). Compendio histórico descriptivo de la Muy Noble y Muy Leal ciudad de Sevilla Metrópoli de Andalucía. Sevilla: Vázquez, Hidalgo y Cía., 1789.

BANDA Y VARGAS, Antonio de la. "La Academia de Bellas Artes y el urbanismo sevillano en el siglo XIX». En Historia del Urbanismo sevillano. Sevilla: Real Academia de Bellas Artes, 1972, pp. 133-165.

BARRIONUEVO FERRER, Antonio. Las formas de crecimiento y construcción de la ciudad. Sevilla: Universidad de Sevilla, 2005.

BernaL, Antonio Miguel. "El Guadalquivir durante el siglo XVIII". En La Sevilla de las Luces. Sevilla: Ayuntamiento, 1991, pp. 59-72.

BONET CORREA, Antonio. El urbanismo en España e Hispanoamérica. Madrid: Cátedra, 1991.

Braojos Garrido, Alfonso. Don José Manuel de Arjona, asistente de Sevilla (1825-1833). Sevilla: Ayuntamiento, 1976.

BRAUNFELS, Wolfgang. Urbanismo occidental. Madrid: Alianza, 1984.

CALATRAva Escobar, Juan. Arquitectura y cultura en el siglo de las Luces. Granada: Universidad, 1999.

Calvo Serraller, Francisco. «Romance de la Sevilla romántica». En Iconografía de Sevilla (1790-1868). Madrid: El Viso, 1991.

Castillo Matos, Manuel; Rodríguez Mateos, Joaquín y Sú́rez Japón, Juan Manuel. Sevilla y su río en el siglo XVIII: un proyecto ilustrado para la mejora del cauce del Guadalquivir. Sevilla: Universidad de Sevilla, 2012.

Collantes de Terán SÁnchez, Antonio; Cruz Villalón, Josefina; Reyes Cano, Rogelio; RodríGUEZ BECERRA, Salvador (dirs.). Diccionario Histórico de las calles de Sevilla. Tres tomos. Sevilla: Consejería de Obras Públicas. Junta de Andalucía, Ayuntamiento, 1993.

Comisaría de la Ciudad de Sevilla para 1992 (ed.). La Sevilla de las Luces. Sevilla: Ayuntamiento, 1991.

Cortés José, Joaquín; García JaÉn, María Josefa; Zoido Naranjo, Florencio. Planos de Sevilla: colección histórica (1771-1918). Sevilla: Ayuntamiento, 1992.

CORTÉs José, Joaquín (dir). Catálogo de cartografía histórica de Sevilla, Sevilla: Junta de Andalucía. Consejería de Obras Públicas y Transportes, 2004.

Defourneaux, Marcelin: Pablo de Olavide el afrancesado. París: 1959 (Trad. castellano. Sevilla: Padilla. Productora Andaluza de Programas, 1990).

EquiPo 28 (ed.). El Río. El Bajo Guadalquivir. Sevilla: 1985.

Espiau Eizaguirre, Mercedes. «Formas que hacen ciudad: notas sobre la arquitectura doméstica sevillana de la segunda mitad del setecientos". Archivo Hispalense, 1990, 224, pp. 137-148.

Espiau EiZAGuirRe, Mercedes. "La realidad y el deseo en una vista de Sevilla de 1825". Archivo Hispalense, 1992, 230, pp. 151-158. 
Espiau Eizaguirre, Mercedes. "Arquitectura y ciudad en la Sevilla decimonónica». Archivo Hispalense, 1995, 237, pp. 163-176.

FERnÁNDez Chaves, Manuel F. Política y administración del abastecimiento de agua en Sevilla durante la Edad Moderna. Sevilla: Diputación, 2012.

FERNÁNDEZ GONZÁLEZ, Alberto. «Arquitectura y mercado en la Sevilla del siglo XIX: la plaza de abastos de Triana». Archivo Hispalense, 2010, 282-284, pp. 465-486.

FERNÁNDEZ GONZÁLEZ, Alberto. "Ciudad y mercado en Sevilla: El trienio liberal (1820-1823)». En SERrano, Felipe (Coord). Docta Minerva. Homenaje a la profesora Luz de Ulierte Vázquez. Jaén: Universidad de Jaén, 2010, pp. 249-260.

FERNÁNDEZ GonZÁlez, Alberto. «Memoria histórica de un fragmento urbano de Sevilla: El espacio de la Encarnación entre los siglos XVI y XXI». En BARRAL RIVAdulLa, María Dolores; Fernández Castiñeiras, Enrique; Fernández Rodríguez, Begoña, y Monterroso Montero, Juan Manuel (coords.). Mirando a Clío: el arte español espejo de su historia. Actas del XVIII Congreso del CEHA. Santiago de Compostela: Universidad de Santiago de Compostela, 2012 [CD].

Flores Moscoso, Ángeles. «Noticias históricas del Castillo de Triana». Archivo Hispalense, 1993, 232, pp. 33-54.

GonzÁlez Cordón, Antonio. Vivienda y Ciudad. Sevilla 1849-1929. Sevilla: Ayuntamiento, 1984.

GONZÁlez de LEón, Félix. Noticia histórica del origen del nombre de las calles de esta Muy Noble, Muy Leal y Muy Heroica ciudad de Sevilla. Sevilla: Imp. de D. José Morales, 1839.

González de León, Félix. Noticia Histórica, Artística y Curiosa de esta Muy Noble, muy leal muy heroica e invicta ciudad de Sevilla, y de muchas casas principales con todo lo que le sirve de adorno artístico, antigüedades, inscripciones y curiosidades que contienen. Sevilla: 1844. (Reimp. Abengoa, 1973).

Gravagnuolo, Benedetto. Historia del urbanismo en Europa (1750-1960). Madrid: Akal, 1998.

GUICHOT Y PARODY, Joaquín. Historia del Excelentísimo Ayuntamiento de la ciudad de Sevilla. Sevilla: 1898. (Colegio de Aparejadores y Arquitectos Técnicos, 1990). Tomo III.

HERNÁNDEZ NÚÑEZ, Juan Carlos. «El granero el cabildo hispalense: Historia y edificación». Archivo Hispalense, 1988, 217, pp. 223-236.

HERNÁNDEZ NÚÑEZ, Juan Carlos. «Transformaciones urbanas en Sevilla durante el siglo XVIII: El derribo del corral de Olmos". Archivo Hispalense, 1993, 232, pp. 89-108.

HERNÁNDEZ NúÑEZ, Juan Carlos. "La construcción de las dependencias catedralicias del ángulo suroeste y su repercusión en el urbanismo sevillano». Archivo Hispalense, 1993, 233, pp. 121-142.

HERNÁNDEZ NúNẼE, Juan Carlos. «Noticias sobre el arco de San Miguel y su derribo en el siglo XVIII". Laboratorio de Arte, 1993, 6, pp. 179-188.

HERNÁNDEZ NúÑEz, Juan Carlos. «Noticias sobre la Alcaicería de la Seda de Sevilla y su transformación en el siglo XVIII». Laboratorio de Arte, 1994, 7, pp. 115-130.

HERNANDO, Javier. Arquitectura en España, 1770-1900. Madrid: Cátedra, 2004.

Kaufmann, Emil. L'architettura dell' Illuminismo. Roma: Einaudi, 1966.

López Gómez, Antonio y MANSO PORTO, Carmen. Cartografía del siglo XVIII. Tomás López en la Real Academia de la Historia. Madrid: Real Academia de la Historia, 2006.

LozAnO BartolozzI, María del Mar. Historia del Urbanismo en España II. Siglos XVI, XVII y XVIII. Madrid: Cátedra, 2011.

Matute y Gaviria, Justino. Anales eclesiásticos y seculares de la Muy Noble y Muy Leal ciudad de Sevilla. Sevilla: Imp. E. Rasco, 1887. (Guadalquivir, 1997) 3 tomos. 
Moral ITUARTE, Leandro del. La obra hidraúlica en la cuenca baja del Guadalquivir (Siglos XVIII-XX). Gestión del agua y organización del territorio. Sevilla: Universidad. Consejería de obras Públicas y Transportes. Ministerio de Agricultura, Pesca y Alimentación, 1991.

MORAL ITUARTE, Leandro del. El Guadalquivir y la transformación urbana de Sevilla (Siglos XVIII-XX). Sevilla: Ayuntamiento, 1992.

Morales SÁnchez, José. La Real Fábrica de Tabacos. Arquitectura, territorio y ciudad en la Sevilla del siglo XVIII. Sevilla: FOCUS, 1991.

Moreno Alonso, Manuel. Sevilla napoleónica. Sevilla: Alfar, 1995.

Moreno Alonso, Manuel. La Revolución "Santa» de Sevilla. Sevilla: Caja San Fernando, 1997.

MORRIS, A. E. J. Historia de la forma urbana. Desde sus origenes hasta la revolución Industrial. Barcelona: Gustavo Gili, 1998.

NúÑEZ CASTAIN, José. Sevilla, centro histórico: la transformación radical de su imagen urbana: génesis y desarrollo del planeamiento urbano en el siglo XIX. Sevilla: ETSA, 1985. Tesis Doctoral de la Universidad de Sevilla.

Ollero Lobato, Francisco. «Propuestas urbanísticas para el área del convento de San Francisco de Sevilla durante la primera mitad del siglo XIX". Archivo Hispalense, 2002, 258, pp. 135-152.

Ollero Lobato, Francisco. Cultura artística y arquitectura en la Sevilla de la Ilustración (1775-1808). Sevilla: Caja San Fernando, 2004.

Ollero Lobato, Francisco. "La Sevilla soñada. Plazas y ciudad en los inicios del siglo XIX". Atrio, 2006, 12, pp. 81-94.

Ollero Lobato, Francisco. "Olavide y las artes en Sevilla». Ilustración y libertades. Revista de Pensamiento e Historia de las Ideas, 2007, 1, pp. 33-55.

Ollero Lobato, Francisco. El Barrio de la Laguna de Sevilla: Diseño Urbano, Razón y Burguesía en el Siglo de las Luces. Sevilla: Universidad de Sevilla, 2012.

Olmedo Granados, Fernando; Cortés, Joaquín (coords.). Andalucía la imagen cartográfica hasta fines del siglo XIX. Sevilla: Instituto de Cartografía de Andalucía, 2011.

PERDICES DE Blas, Luis. Pablo de Olavide (1725-1803), el ilustrado. Madrid: Universidad Complutense, 1993.

Perdices DE Blas, Luis. «Pablo de Olavide (1725-1803) a través de sus escritos». Cuadernos Dieciochistas, 2003, 4, pp. 13-30.

PERDICES DE BLAS, Luis. «El desarrollo intelectual de Jovellanos en la Sevilla de Olavide (17681776)». Dieciocho, 2013, 36.1, pp. 51-78.

PEROSINI, Scipión. Memorias sobre el estado actual del Río Guadalquivir, modo de facilitar y asegurar su navegación desde el mar hasta Sevilla, y precaverla de los daños que padece en las Ynundaciones. Biblioteca Colombina. Mss. 64-8-127.

Ponce Ortiz De Insagurbe, Mercedes; SÁnchez SÁnchez, José. Sevilla: Arquitectura y ciudad militar. El cuartel de la Carne, patrimonio recuperado. Sevilla: Diputación, 2004.

PONZ, Antonio. Viage de España, en que se da noticia de las cosas más apreciables, y dignas de saberse, que hay en ella. Tomo IX. (2. ${ }^{a}$ ed.) Madrid: Imp. de Ibarra, Hijos y Cía, 1786.

Posada Simeón, J. Carlos; Peñalver Gómez, Patricio. Cartografía histórica en la Biblioteca de la Universidad de Sevilla. Sevilla: Universidad de Sevilla, 2010.

Rabanal Yus, Aurora. Las Reales Fundiciones españolas del siglo XVIII. Madrid: Servicio de Publicaciones del EME, 1990.

RoIg Del Negro, Álvaro Marcelo. La Real Fundición de Cañones de Bronce de Sevilla, bistoria, arquitectura y urbanismo de una fabrica del siglo XVIII: el edificio como condicionante en la conformación del barrio de San Bernando. Sevilla: Universidad de Sevilla. Tesis Doctoral dirigida por Carlos M. FERNÁNDEZ MARTíneZ, 2001. 
Rodríguez Barberán, Francisco Javier (Comisario). La Sevilla de Richard Ford 1830-1833. Sevilla: Fundación El Monte, 2007.

SAMBricio, Carlos. «El urbanismo de la Ilustración: 1750-1814». En Viviendas y urbanismo en España. Madrid: Banco Hipotecario, 1982, pp. 138-157.

SAMBricio, Carlos. La arquitectura española de la Ilustración. Madrid: Instituto de la Administración Pública, 1986.

SAMBricio, Carlos. Territorio y ciudad en la España de la Ilustración. Madrid: Ministerio de Obras Públicas y Transportes, 1991. 2 Vols.

SÁnchez-Cortegana, José María; Ponce-OrTiz, Mercedes. «Sevilla: Arquitectura y ciudad militar de 1750 a 1800». En Milicia y sociedad ilustrada en España y América (1750-1800). Actas de las XI Jornadas Nacionales de Historia Militar. Madrid: Deimos, 2003, vol. 2, pp. 451-482.

SERRERA, Juan Miguel et al. Iconografía de Sevilla. 1650-1790. Madrid: El Viso, 1989.

SICA, Paolo. Historia del Urbanismo. Madrid: Instituto de Administración Local, 1981. 4 vols.

SocIEDAD estatal de Gestión de Activos (ed.). Sevilla, Puerto y puerta de América. Sevilla: 1996.

SOBRINO Simal, Vicente Julián (coord.). Luces sobre la memoria: La Real Fábrica de Artillería de Sevilla. Patrimonio Histórico Militar e Industrial. Madrid: Ministerio de Defensa, 2011.

SuÁREZ GaRmendia, José Manuel. Arquitectura y Urbanismo en la Sevilla del siglo XIX. Sevilla: Diputación, 1986.

SuÁrez Garmendia, José Manuel. «El Patín de las Damas: Un lugar olvidado». Laboratorio de Arte, 1988, 1, pp. 199-213.

SuÁREZ GARMENDIA, José Manuel. «La puerta Nueva o de San Fernando». Laboratorio de Arte,1989, 2, pp. 173-182.

SuÁrez Garmendia, José Manuel. «En torno al extramuros de Sevilla: el plano de 1836». Laboratorio de Arte, 1999, 12, pp. 345-354.

SuÁrez GaRmendia, José Manuel. «La Plaza de Armas: evolución de una ocupación en el perímetro exterior de Sevillaw. Laboratorio de Arte, 2005, 18, pp. 493-504.

SuÁrez Garmendia, José Manuel. «El urbanismo hacia 1830». En Rodríguez Barberán, Francisco Javier (Comisario). La Sevilla de Richard Ford 1830-1833. Sevilla: Fundación El Monte, 2007, pp. 191-204.

SuÁREZ GARMENDIA, José Manuel. «La aportación de los conventos desamortizados a la creación de tejido urbano de Sevilla en el siglo XIX". En La ciudad oculta: el universo de las clausuras de Sevilla. Sevilla: Fundación Cajasol, 2009, pp. 65-89.

TERÁn, Fernando de. Historia del Urbanismo en España III. Siglos XIX y XX. Madrid: Cátedra, 1999.

Vega GonzÁlez, Jesusa. Ciencia, arte e ilusión en la España ilustrada. Madrid: CSIC, 2010.

VelázQuez y SÁNCHEZ, José. Anales de Sevilla de 1800 a 1850. Sevilla: Imprenta y librería de Hijos de Fe, 1872. (Sevilla: Ayuntamiento, 1994).

VIDLER, Anthony. El espacio de la Ilustración. La teoría arquitectónica en Francia a finales del siglo XVIII. Madrid: Alianza, 1997.

VIOQUe CUBERO, R. et al. Apuntes sobre el origen y evolución morfológica de las plazas del casco histórico de Sevilla. Sevilla: Ayuntamiento. Consejería de obras públicas y transportes de la Junta de Andalucía, 1987.

ZELler, Olivier. Historia de la Europa urbana III. La ciudad moderna. Valencia: Servei de Publicacions, 2011. 
